Why do crop models diverge substantially in climate impact projections? A comprehensive analysis based on eight barley crop models

Tao, Fulu

2020-02-15

Tao , F , Palosuo , T , Rötter , R P , Díaz-Ambrona , C G H , Inés Mínguez , M , Semenov , M A , Kersebaum , K C , Cammarano , D , Specka, X, Nendel , C , Srivastava , A K, Ewert , F, Padovan, G, Ferrise , R, Martre , P, Rodríguez, L, Ruiz-Ramos, M, Gaiser , T, Höhn , J G , Salo , T , Dibari , C \& Schulman , A H 2020 , ' Why do crop models diverge substantially in climate impact projections? A comprehensive analysis based on eight barley crop models ' , Agricultural and Forest Meteorology , vol. 281 , 107851 . https://doi.org/10.1016/j.agrformet.2019.107

http://hdl.handle.net/10138/321942

https://doi.org/10.1016/j.agrformet.2019.107851

cc_by_nc_nd

acceptedVersion

Downloaded from Helda, University of Helsinki institutional repository.

This is an electronic reprint of the original article.

This reprint may differ from the original in pagination and typographic detail.

Please cite the original version. 


\title{
Why do crop models diverge substantially in climate impact projections? A comprehensive analysis based on eight barley crop models
}

\author{
Fulu Tao ${ }^{\mathrm{a}, *}$, Taru Palosuo ${ }^{\mathrm{a}}$, Reimund P. Rötter ${ }^{\mathrm{b}, \mathrm{c}}$, Carlos Gregorio Hernández Díaz-Ambrona ${ }^{\mathrm{d}}$, \\ M. Inés Mínguez ${ }^{\mathrm{d}}$, Mikhail A. Semenov ${ }^{\mathrm{e}}$, Kurt Christian Kersebaum ${ }^{\mathrm{f}}$, Davide Cammarano ${ }^{g}$, \\ Xenia Specka ${ }^{\mathrm{f}}$, Claas Nendel ${ }^{\mathrm{f}}$, Amit Kumar Srivastava ${ }^{\mathrm{h}}$, Frank Ewert ${ }^{\mathrm{f}, \mathrm{h}}$, Gloria Padovan ${ }^{\mathrm{i}}$, \\ Roberto Ferrise ${ }^{\mathrm{i}}$, Pierre Martre ${ }^{\mathrm{j}}$, Lucía Rodríguez ${ }^{\mathrm{d}}$, Margarita Ruiz-Ramos ${ }^{\mathrm{d}}$, Thomas Gaiser ${ }^{\mathrm{h}}$, \\ Jukka G. Höhn ${ }^{\mathrm{a}}$, Tapio Salo ${ }^{\mathrm{a}}$, Camilla Dibari ${ }^{\mathrm{i}}$, Alan H. Schulman ${ }^{\mathrm{a}, \mathrm{k}}$ \\ ${ }^{a}$ Natural Resources Institute Finland (Luke), Helsinki, Finland \\ ${ }^{\mathrm{b}}$ Tropical Plant Production and Agricultural Systems Modelling (TROPAGS), Department of Crop Sciences, Georg-August-University of Göttingen, Germany \\ ${ }^{c}$ Centre for Biodiversity and Sustainable Land Use (CBL), Georg-August-University of Göttingen, Göttingen, Germany \\ ${ }^{\mathrm{d}}$ AgSystems-CEIGRAM Research Centre for Agricultural and Environmental Risk Management- Universidad Politécnica de Madrid, Spain \\ ${ }^{\mathrm{e}}$ Rothamsted Research, Harpenden, Herts, UK \\ ${ }^{\mathrm{f}}$ Leibniz Centre for Agricultural Landscape Research, Müncheberg, Germany \\ ${ }^{\mathrm{g}}$ Department of Agronomy, Purdue University, West Lafayette, IN 47907, USA \\ ${ }^{\mathrm{h}}$ Crop Science Group, INRES, University of Bonn, Bonn, Germany \\ ${ }^{\mathrm{i}}$ Department of Agriculture, food, environment and forestry, University of Florence, Firenze, Italy \\ ${ }^{\mathrm{j}}$ LEPSE, Univ. Montpellier, INRA, Montpellier SupAgro, 34060 Montpellier, France \\ ${ }^{\mathrm{k}}$ Institute of Biotechnology and Viikki Plant Science Centre, University of Helsinki, Helsinki, Finland
}

\section{A R T I C L E I N F O}

\section{Keywords:}

Agriculture

Climate change

Crop growth simulation

Impact

Model improvement

Uncertainty

\begin{abstract}
A B S T R A C T
Robust projections of climate impact on crop growth and productivity by crop models are key to designing effective adaptations to cope with future climate risk. However, current crop models diverge strongly in their climate impact projections. Previous studies tried to compare or improve crop models regarding the impact of one single climate variable. However, this approach is insufficient, considering that crop growth and yield are affected by the interactive impacts of multiple climate change factors and multiple interrelated biophysical processes. Here, a new comprehensive analysis was conducted to look holistically at the reasons why crop models diverge substantially in climate impact projections and to investigate which biophysical processes and knowledge gaps are key factors affecting this uncertainty and should be given the highest priorities for improvement. First, eight barley models and eight climate projections for the 2050s were applied to investigate the uncertainty from crop model structure in climate impact projections for barley growth and yield at two sites: Jokioinen, Finland (Boreal) and Lleida, Spain (Mediterranean). Sensitivity analyses were then conducted on the responses of major crop processes to major climatic variables including temperature, precipitation, irradiation, and $\mathrm{CO}_{2}$, as well as their interactions, for each of the eight crop models. The results showed that the temperature and $\mathrm{CO}_{2}$ relationships in the models were the major sources of the large discrepancies among the models in climate impact projections. In particular, the impacts of increases in temperature and $\mathrm{CO}_{2}$ on leaf area development were identified as the major causes for the large uncertainty in simulating changes in evapotranspiration, above-ground biomass, and grain yield. Our findings highlight that advancements in understanding the basic processes and thresholds by which climate warming and $\mathrm{CO}_{2}$ increases will affect leaf area development, crop evapotranspiration, photosynthesis, and grain formation in contrasting environments are needed for modeling their impacts.
\end{abstract}

\footnotetext{
* Corresponding author.

E-mail address: fulu.tao@luke.fi (F. Tao).
} 


\section{Introduction}

Impacts of climate change on future crop productivity and food security have been of key concern because agricultural production risks may increase, and food security be threatened, by climate change and increasing extreme climate events (Lobell et al., 2011; Olesen et al., 2011; Porter et al., 2014; Rötter et al., 2018 ). Crop models are popular tools to project climate change impacts on future agricultural production, driven by climate projections from global climate models (GCMs) (White et al., 2011; Porter et al., 2014). However, the projections of climate change impacts are plagued with uncertainties from many sources, such as climate projections, crop model parameters, and crop model structure (Tao et al., 2009, 2018; Rötter et al., 2011;Rötter, 2014; Asseng et al., 2013, 2015; Wallach et al., 2017; Wallach and Thorburn, 2017). These uncertainties have to be quantified and reduced as much as possible in order to better assess climate risk and inform effective adaptation (Tao et al., 2018). Recently, some studies have consistently indicated that the uncertainty from crop model structure is larger than those from climate projections and crop model parameters (Asseng et al., 2013, 2015; Bassu et al., 2014; Li et al., 2015; Zhang et al., 2017; Tao et al., 2018). Therefore, the most effective way to improve climate change impact projections is to reduce the uncertainty from crop model structure through model comparison and improvement, combined with considerations of other sources of uncertainty such as model parameters (Wang et al., 2017; Challinor et al., 2018; Tao et al., 2018; Rötter et al., 2018). Major international efforts, such as the Modelling European Agriculture with Climate Change for Food Security (MACSUR) project (Ewert et al., 2015) and the Agricultural Model Inter-comparison and Improvement Project (AgMIP) (Rosenzweig et al., 2013; Ruane et al., 2017), have tried to compare and improve crop models, and quantify, manage or reduce uncertainty from model structure in projecting climate impact on crop productivity (e.g. Palosuo et al., 2011; Rötter et al., 2012; Asseng et al., 2013, 2015; Bassu et al., 2014; Li et al., 2015; Martre et al., 2015; Pirttioja et al., 2015; Durand et al., 2018; Maiorano et al., 2017; Hasegawa et al., 2017; Müller et al., 2017; Wang et al., 2017; Tao et al., 2018).

Previous studies tried to compare or improve crop models mainly by simulating the impact of one single climate variable, such as temperature (Zhang and Tao, 2013; Asseng et al., 2013, 2015; Maiorano et al., 2017; Wang et al., 2017) or rising atmospheric $\mathrm{CO}_{2}$ concentration (Durand et al., 2018; Hasegawa et al., 2017) on crop development, growth, water use, and grain formation. These studies documented that although individual crop models were able to simulate observed grain yields fairly well, yield projection in response to climate warming or elevated $\mathrm{CO}_{2}$ varied significantly among the crop models because of quite different temperature or $\mathrm{CO}_{2}$ relationships applied in the models (Asseng et al., 2013, 2015; Zhang and Tao, 2013; Durand et al., 2018; Wang et al., 2017; Hasegawa et al., 2017). These studies are important in understanding the uncertainty and for improving models regarding the impact of a specific climate variable. However, final grain yields are subject to the interactive impacts of multiple climate change factors and many interrelated biophysical processes, such as crop phenological development, leaf area development, evapotranspiration (ET), photosynthesis, and grain formation (Porter and Gawith, 1999). The impacts of different climate variables on multiple biophysical processes and consequently on final grain yields can be offset or additive (Swann et al., 2016; Tao et al., 2017). A comprehensive analysis that accounts for the interactive impacts of multiple climate variables and their interactions, as well as for the multiple biophysical processes and their interactions, is necessary in order to understand, in a holistic way, why climate impact projections by different crop models are so different. Furthermore, since most of the biophysical processes in crop development, growth, water use, and grain formation are directly or indirectly affected by temperature and $\mathrm{CO}_{2}$ relationships in crop models, it is necessary to identify, in more detail, which biophysical processes and knowledge gaps are the key sources or bottlenecks for the uncertainty in climate impact projections and therefore should be given the highest priorities for improvement.

As an outgrowth of our previous study (Tao et al., 2018), here we first applied eight barley models and eight climate projections for the 2050s to quantify the uncertainty from crop model structure in climate impact projections for barley growth and yield at two sites with contrasting climate: Jokioinen, Finland in the Boreal climatic zone and Lleida, Spain in the Mediterranean climatic zone. The climate projections, the impact projections from each single model, as well as the uncertainties in impact projections, provide the rationale, target, and basis for the following analyses. We then conducted sensitivity analyses for each of the eight crop models based on their responses to major climatic variables including temperature, precipitation, irradiation, and $\mathrm{CO}_{2}$, as well as their interactions. Finally, we conducted a comprehensive analysis to investigate why crop models diverge substantially in climate impact projections. Differently from previous model intercomparison studies (Asseng et al., 2013, 2015; Bassu et al., 2014; Li et al., 2015; Castañeda et al., 2015; Hasegawa et al., 2017) and impact response surface studies (Pirttioja et al., 2015), we aimed here, for the first time, to gain insights into the reasons underlying the divergence in climate impact projections in a holistic way.

\section{Materials and methods}

\subsection{Study sites}

Two study sites with contrasting climates were selected for this study. They represent the North and South of current agro-climatic conditions for barley cultivation areas in Europe. The general information on the geographical location, climate, and barley cultivation is presented in Table 1.

\subsection{Crop models and data}

Eight different barley models with varying complexity were applied: APSIM 7.7 (AP, Holzworth et al., 2014), CropSyst 4.15.04 (CS, Stöckle et al., 2014), HERMES 4.26 (HE, Kersebaum, 2007), MCWLA 2.0 (MC, Tao et al., 2009), MONICA 1.2.5 (MO, Nendel et al., 2011), SIMPLACE < Lintul2, Slim > (SI, Angulo et al., 2013), SiriusQuality 2.0 (SQ, Martre et al., 2006), and WOFOST 7.1 (WO, Boogaard et al., 1998). The eight can be used as good examples to investigate the divergences among crop models because they are process-based and widely used for climate impact sudies, have quite different model structures (Tables S1S9), and produce quite different climate impact projections (Tao et al., 2018). The use of eight different models is sound for this purpose, although the use of more different models could be better. All the models simulate crop phenological development, growth, and productivity on a daily time step. Different approaches are applied in simulating major processes in these models, as detailed in Tables S1-S9.

Briefly, for crop phenological development, most of the models account for the effects of temperature, day length, and vernalization except $S I$ and $W O$, which do not account for vernalisation and may have uncertainty in simulating the development rate of cultivars needing vernalisation. $A P, C S, H E$, and $M O$ also account for the effects of water or nutrient stress on crop phenological development. $S Q$ accounts for the impact of water deficit on phenological development through its effect on canopy temperature. For leaf area development, a carbon (biomass)-dependent approach is used in most of the models, except $M C$ and $S Q$, which use a temperature- and water/nitrogen-driven approach. For light utilization, a light-use-efficiency (LUE) approach is applied in most of the models except $H E, M C, M O$, and $W O$, which use a gross photosynthesis minus respiration approach. In CS, a transpiration efficiency biomass growth approach was also used. For ET, a Penman or Penman-Monteith approach is used in most of the models based on the 'big-leaf' approach. A dry matter partitioning approach is used during reproductive stages in most of the models to simulate yield formation, 
except for $C S$ and $M C$, which use a harvest index approach. The LUE, transpiration efficiency, or both are modified by $\mathrm{CO}_{2}$ concentration using empirical functions in most of the models, except $H E, M C$, and $M O$, which use the Farquhar model, and WO, which uses a photosynthesis-light response curve.

Detailed field trial data, including soil properties, tillage, fertilization, phenology, above-ground biomass at anthesis and maturity, yield, and agronomic management practices were obtained for two growing seasons at Jokioinen in 2002 and 2009 (Salo et al., 2016) and for three growing seasons at Lleida from 1996 to 1999 (Cantero-Martinez et al., 2003). The barley cultivars in the experiments were Annabell at Jokioinen and Hispanic at Lleida. The spring barley cultivar at Jokioinen didn't need vernalisation although the winter barley cultivar at Lleida did. The soils were Vertic Cambisol with a clay texture at Jokioinen and typic Xerofluvent with a loam texture at Lleida. Barley cultivation was rain-fed at both sites. Based on the experimental data on barley phenology and yield, agronomic management practices, and environmental conditions at Jokioinen and Lleida, for each crop model, the genetic parameters were calibrated and validated using the traditional trialand-error method. This was done based on one year's trial data and then validated against the remaining experimental data. At each site, for each model, with its calibrated parameters, the differences between simulated and observed flowering and maturity dates were less than 5 days, and the discrepancies between observed and simulated yield were less than $20 \%$ (Tao et al., 2018).

Observed daily weather data for solar radiation, minimum (Tmin) and maximum (Tmax) temperature, precipitation, wind speed and air humidity during the period 1980-2010 at the two sites were obtained from the Finnish Meteorological Institute, the Spanish Agencia Estatal de Meteorología (AEMET), and other sources (Pirttioja et al., 2015). For future climate, eight contrasting GCMs were selected from the Coupled Model Inter-comparison Project Phase 5 (CMIP5) ensemble, driven by the emission scenario of Representative Concentration Pathway (RCP) 8.5 for the period of the 2050s, a reference for possible futures with high greenhouse gas emissions. The RCP8.5 scenario was chosen because very recent publications have shown that actual emissions continue to be close to the high end of the projections. Currentlym the high end RCP8.5 appears to be the "business-as-usual" case; there are no signs that this will change in the near future (e.g., Smith and Myers, 2018).

The eight GCMs were selected based on their climatic sensitivity to preserve the range of uncertainties in CMIP5 (Tao et al., 2018), including ACCESS1-3 (ACCESS, Rashid et al., 2013), EC-EARTH (Hazeleger et al., 2012), GFDL-CM3 (GFDL, Dunne et al., 2013), GISSE2-R-CC (GISS, Nazarenko et al., 2015), HadGEM2-ES (HADGEM, Jones et al., 2011), IPSL-CM5A-MR (IPSL, Dufresne et al., 2013), MIROC-ESM (MIROC, Watanabe et al., 2011), and MPI-ESM-MR (MPI, Raddatz et al., 2007). The number of GCMs used is a rough compromise between perfectness and computing cost. For crop model simulations, daily local-scale scenarios of 31 years for the 2050s were constructed for the two study sites and each of the eight GCMs by applying change factors to observed weather data for the period 1980-2010, as described in detail in Tao et al. (2018). Based on the eight climate projections for the 2050s at Jokioinen, Tmin and Tmax during the growing season were projected to increase by $1.5{ }^{\circ} \mathrm{C}$ to $4.1{ }^{\circ} \mathrm{C}$ and $1.5{ }^{\circ} \mathrm{C}$ to $4.2^{\circ} \mathrm{C}$, respectively, relative to $1981-2010$ (Fig. S1a). Precipitation was projected to change by $-2 \%$ to $+13 \%$ and solar radiation by $-2 \%$ to $+12 \%$. At Lleida, Tmin and Tmax were projected to increase by $1.3{ }^{\circ} \mathrm{C}$ to $2.6{ }^{\circ} \mathrm{C}$ and $1.3{ }^{\circ} \mathrm{C}$ to $3.6{ }^{\circ} \mathrm{C}$, respectively. Precipitation was projected to change by $-27 \%$ to $+15 \%$ and solar radiation by $-1 \%$ to $+10 \%$ (Fig. S1b).

\subsection{Climate change impact projections for the 2050s}

Each of the eight calibrated barley models were run for 30 growing seasons with annual re-initialisation using the baseline (1980-2010) 
weather data and each of the eight climate projections for the 2050s, respectively. Atmospheric $\mathrm{CO}_{2}$ concentration was set at $360 \mathrm{ppm}$ for the baseline and $560 \mathrm{ppm}$ for the 2050s according to the emission scenario RCP 8.5. The typical sowing date, agronomic management, and cultivars from the field trials used for model calibration were applied. Then for each of the eight barley models and each of the eight climate projections for the 2050s, we computed the projected changes in barley maturity date, maximum leaf area index (LAImax), ET, above-ground biomass, and yield in the 2050s relative to 1981-2010, based on the yearly changes between the corresponding 30 -year simulations in the two time periods.

\subsection{Model sensitivity analysis to multiple climate variables and their interactions}

In order to investigate the reasons underlying the discrepancies in climate change impact projections by different crop models, the sensitivity of crop growth and yield to changes in temperature, precipitation, solar radiation, $\mathrm{CO}_{2}$, and their interactions for each of the eight crop models was analyzed, respectively. Considering the projected climate changes at the two sites in the 2050s (Fig.S1), based on the daily weather data for 1980-2010, the sensitivity of crop growth and yield to changes in temperature, precipitation, solar radiation, and $\mathrm{CO}_{2}$ was investigated with daily maximum and minimum temperature changed from -3 to $+7{ }^{\circ} \mathrm{C}$ by steps of $1{ }^{\circ} \mathrm{C}$; with daily precipitation changed by $-20 \%,-10 \%,-5 \%, 5 \%, 10 \%$, and $20 \%$; with daily solar radiation changed by $-15 \%,-10 \%,-5 \%, 5 \%, 10 \%$, and $15 \%$; and with either $360,450,560,640$, or $720 \mathrm{ppm} \mathrm{CO}_{2}$, respectively. The above sensitivity analysis methods have been commonly used (e.g., Asseng et al., 2013; Bassu et al., 2014; Li et al., 2015) and are acceptable for the purpose of this study. The sensitivity of crop growth and yield to the joint changes in temperature, precipitation, solar radiation, and $\mathrm{CO}_{2}$ was investigated with the eight simulation settings in Table 2 .

The interaction effects of the eight simulation settings $\left(\mathrm{IM}_{\mathrm{i}}\right)$ prescribed in Table 2 were estimated as:

$$
\begin{aligned}
I M_{i}= & S_{i\left(\text { Temperature } \times \text { Precipitation } \times \text { Radiation } \times \mathrm{CO}_{2}\right)}-S_{i(\text { Temperature })}-S_{i(\text { Precipitation })} \\
& -S_{i(\text { Radiation })}-S_{i\left(\mathrm{CO}_{2}\right)},
\end{aligned}
$$

where, $S_{i}$ (Temperature $\times$ Precipitation $\times$ Radiation $\times \mathrm{CO}$ ) is the simulated effects on maturity date, LAImax, ET, above-ground biomass, or yield with the simulation setting $i$ in Table 2 accounting for the joint changes in all the

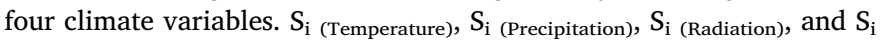
(CO2) are the simulated main effects on maturity date, LAImax, ET, above-ground biomass, or yield accounting for the change in a single climate variable, i.e. temperature, precipitation, solar radiation, and $\mathrm{CO}_{2}$, respectively, prescribed in the simulation setting $i$ in Table 2 . The $\mathrm{IM}_{\mathrm{i}}$ includes the interaction effects from all the two-way, three-way and four-way interactions among the four climate variables.

\subsection{Model inter-comparisons and analyses}

For each of the eight crop models, we first computed the simulated changes in barley maturity date, LAImax, ET, above-ground biomass, and yield based on the 30-year simulations for each setting of the sensitivity analyses, relative to the 30-year simulations for the baseline
(1981-2010). Then we compared the differences and calculated the standard deviations of crop growth and yield responses to changes in temperature, precipitation, solar radiation, $\mathrm{CO}_{2}$, and their interactions among the eight crop models based on 30-year mean in order to investigate the variability among the models. Finally, we investigated the reasons underlying the differences in climate impact projections by different crop models. Pearson correlation analysis was conducted among maturity date, LAImax, ET, above-ground biomass, and yield to understand which processes were important in determining the change in final grain yield for each crop model. The significance of correlations was tested using the two-tailed method. In addition, we also collected the controlled environment experiment data in the literature for benchmarking the models.

\section{Results}

3.1. Projected climate change impacts on barley development, growth, and yield in the $2050 \mathrm{~s}$

In the 2050s, under the eight climate projections, the barley maturity date was projected to advance at both Jokioinen and Lleida, however, by different magnitudes among the eight models and climate projections (Fig. 1a, b). In particular, $M O$ projected the largest advancement in maturity date at Jokioinen, and $A P$ projected the least advancement at Lleida, among the eight crop models. The projected changes in LAImax diverged substantially among the eight crop models and climate projections at both Jokioinen and Lleida (Fig. 1c, d). A large decrease in LAImax was projected by $C S, M O$, and $S I$ at Jokioinen, and by $C S$ and $S I$ at Lleida. In contrast, a large increase in LAImax was projected by $M C$ at Jokioinen, and by $A P$ and $M C$ at Lleida (Fig. 1c, d). ET was projected to decrease generally, however, by different magnitudes among the eight crop models and climate projections at both Jokioinen and Lleida, except for $S I$ and $W O$ at Jokioinen (Fig. 1e, f). As a result, the projected changes in above-ground biomass and grain yield diverged greatly at both Jokioinen and Lleida (Fig. 1g, h, i, j). Grain yield and above-ground biomass were projected to greatly decrease by $C S, M O, S I$, and $W O$, but increase slightly for $M C$ and $S Q$ at Jokioinen; at Lleida, they were projected to strongly decrease for CS and SI, while strongly increase for $M C$ and $H E$ (Fig. $1 \mathrm{~g}, \mathrm{~h}, \mathrm{i}, \mathrm{j}$ ).

The standard deviations of the projected changes in crop growth period, LAImax, ET, biomass, and yield showed that the crop models have the largest uncertainty in simulating climate change impacts on crop yield, biomass, and LAImax at Lleida across the eight crop models and the eight climate projections (Fig. 1k). At Jokioinen, crop models have the largest uncertainty in simulating crop LAImax (Fig. 1k). Across the eight climate projections, the projected yield changes were most variable for $H E$, $W O$, and $M O$ at Lleida, and the projected LAImax changes were most variable for $C S, M O$, and $A P$ (Fig. 11). For each individual crop model, the projected changes in LAImax, above-ground biomass, and grain yield were consistent. Correlation analyses showed that the projected yield changes were significantly and positively correlated with the projected changes in above-ground biomass, ET, maturity date, and LAImax for most of the models, but not all of them (Tables S12-S19). For example, at Jokioinen, the projected yield changes were not significantly and positively correlated with changes in maturity date for $S Q$ and in LAImax for $H E$. At Lleida, the projected

Table 2

\begin{tabular}{|c|c|c|c|c|c|c|c|c|}
\hline \multirow[t]{2}{*}{ Variable } & \multicolumn{8}{|c|}{ Simulation settings } \\
\hline & I & II & III & IV & $\mathrm{V}$ & VI & VII & VIII \\
\hline Change in daily $\operatorname{Tmax}$ and $\operatorname{Tmin}\left({ }^{\circ} \mathrm{C}\right)$ & +2 & +2 & +4 & +4 & +2 & +2 & +4 & +4 \\
\hline Change in daily precipitation (\%) & -10 & +10 & -20 & +20 & -10 & +10 & -20 & +20 \\
\hline Change in daily solar radiation (\%) & +10 & +10 & +10 & +10 & +10 & +10 & +10 & +10 \\
\hline Change in $\mathrm{CO}_{2}(\mathrm{ppm})$ & +90 & +90 & +90 & +90 & +200 & +200 & +200 & +200 \\
\hline
\end{tabular}

Settings for sensitivity analysis of crop growth and yield to joint changes in temperature, precipitation, solar radiation, and $\mathrm{CO}_{2}$, relative to $1981-2010$. 

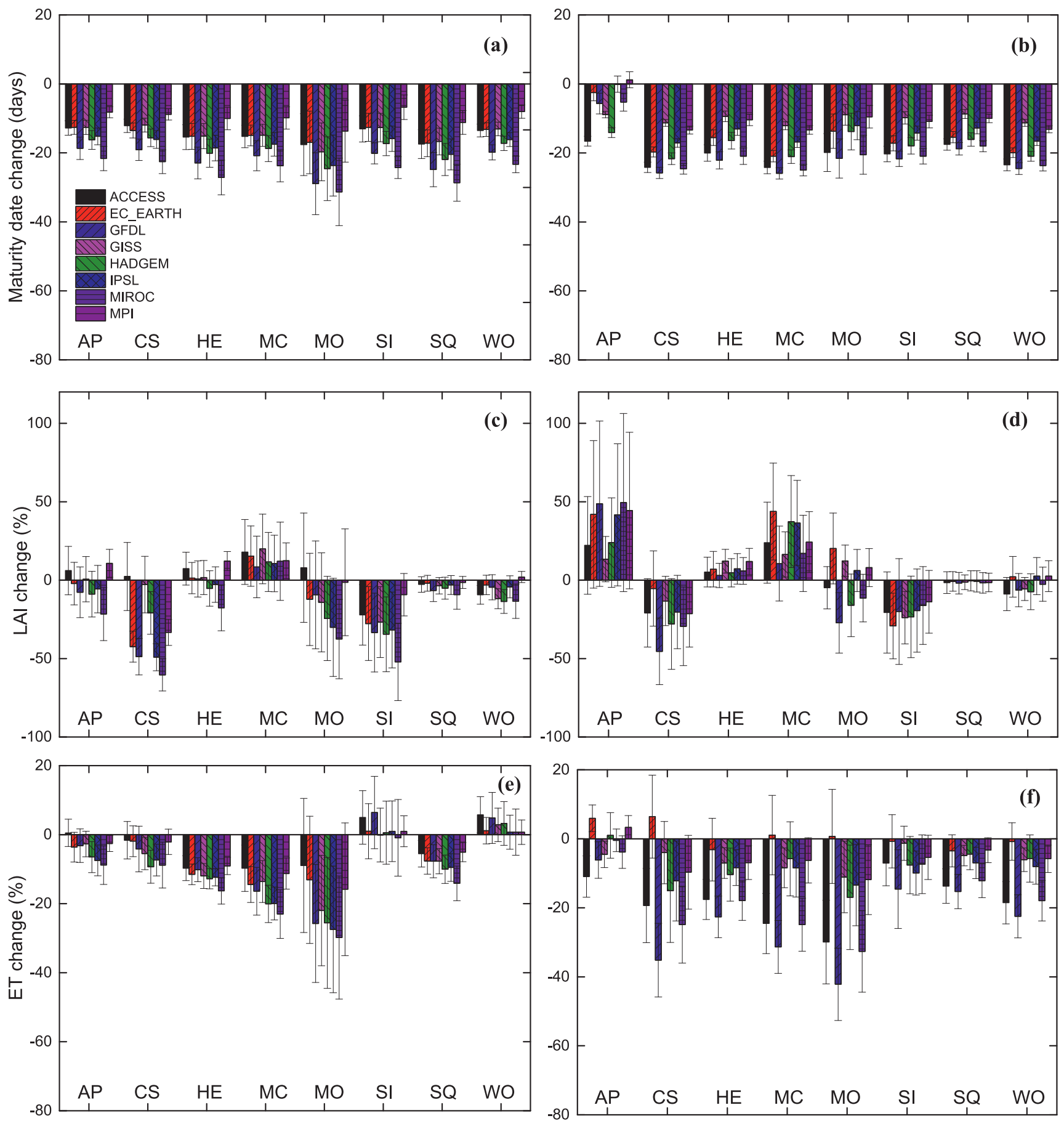

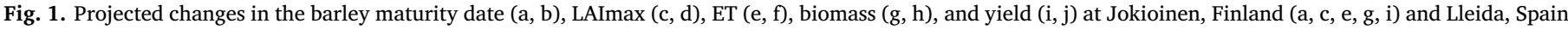

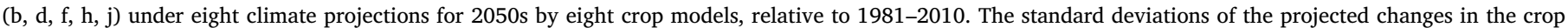

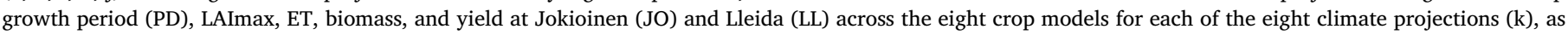

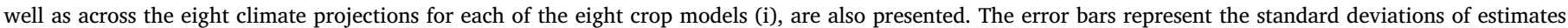
based on the 30 years simulation results.

changes in grain yield were not significantly and positively correlated with changes in maturity date for $A P, C S, M O, S Q$, and $S I$, in ET for $C S$ and $S Q$, and in LAImax for $A P, M O, H E$, and $S Q$ (Tables S12-S19).

\subsection{Responses of crop growth and yield to $\mathrm{CO}_{2}$}

The barley maturity date was generally not affected by rising $\mathrm{CO}_{2}$ for any of the models except $M O$ at Jokioinen (Fig. 2a, b). Simulated changes in LAImax with rising $\mathrm{CO}_{2}$ greatly diverged among the eight crop models, ranging on average from $1.2 \%$ (for $S Q$ ) to $52.6 \%$ (for $M O$ ) at Jokioinen, and from $0.0 \%$ (for $S Q$ ) to $101.3 \%$ (for $S I$ ) at Lleida with $720 \mathrm{ppm} \mathrm{CO}$ relative to $360 \mathrm{ppm} \mathrm{CO}$ (Fig. 2c, d). ET was projected to decrease with rising $\mathrm{CO}_{2}$ by most of the crop models except $S I$, which didn't account for impact of $\mathrm{CO}_{2}$ on ET (Fig. 2e, f). The simulated impacts of rising $\mathrm{CO}_{2}$ on above-ground biomass and grain yield strongly diverged among the models too, ranging from $16.0 \%$ (10.7\%) to $76.1 \%$ (78.9\%) for above-ground biomass (grain yield) at Jokioinen and from $24.1 \%(22.3 \%)$ to $105.0 \%(104.4 \%)$ at Lleida with $720 \mathrm{ppm} \mathrm{CO}_{2}$ 

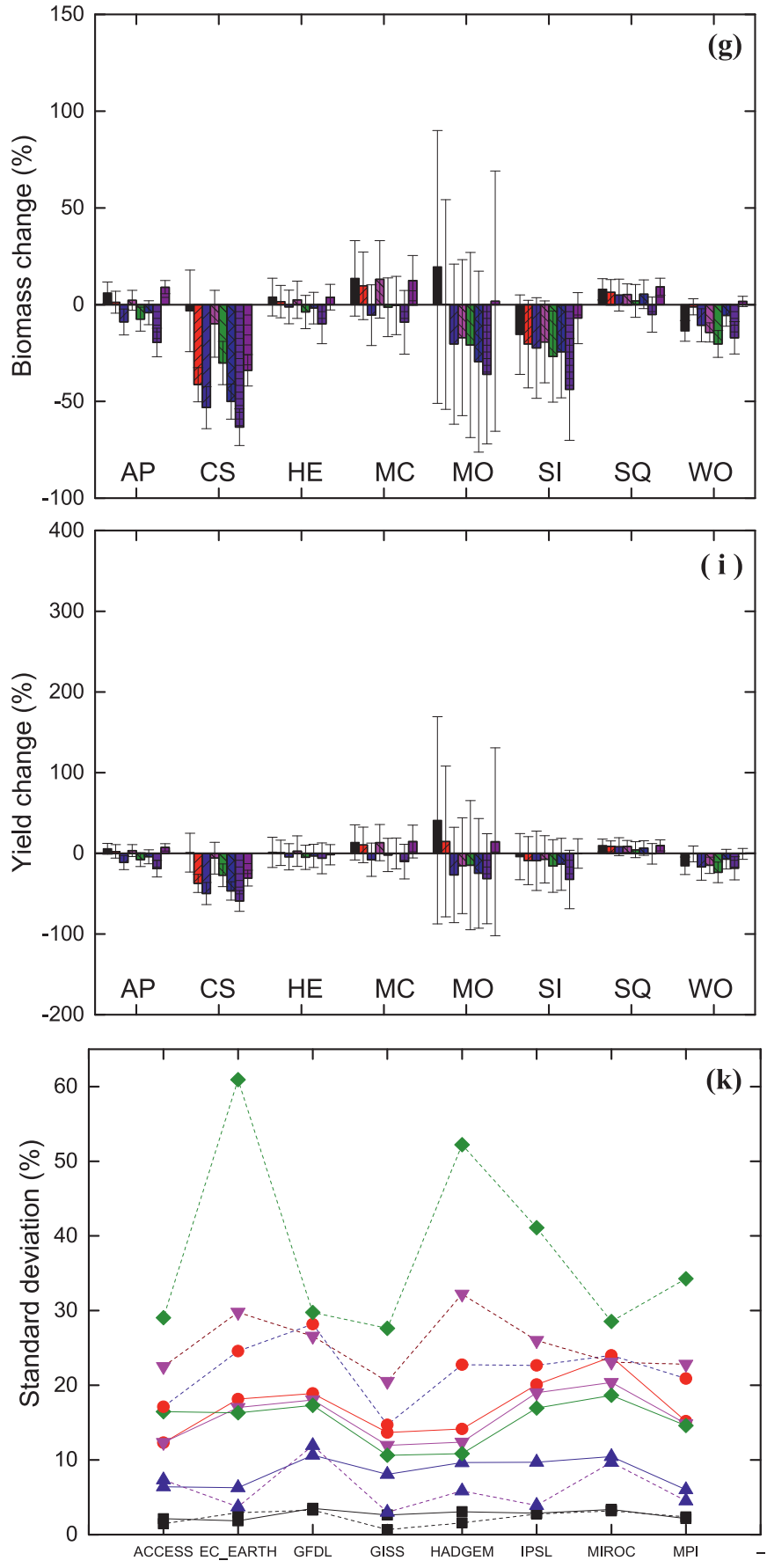
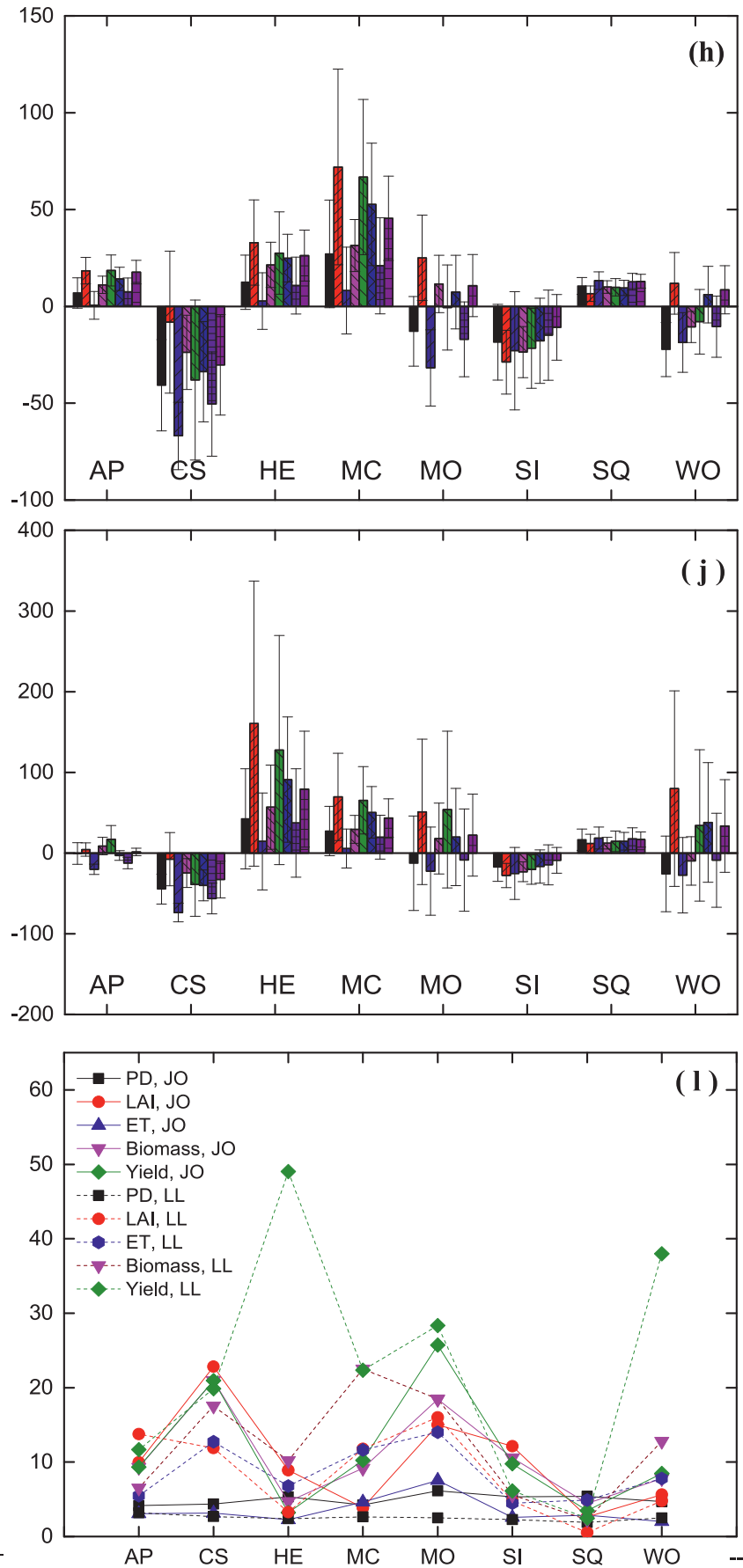

Fig. 1. (continued)

relative to $360 \mathrm{ppm} \mathrm{CO}_{2}$ (Fig. $2 \mathrm{~g}, \mathrm{~h}, \mathrm{i}, \mathrm{j}$ ). The standard deviation of the projected changes across the eight crop models showed that crop models had the largest uncertainty in simulating the impacts of elevated $\mathrm{CO}_{2}$ on LAImax at Lleida, and on yield, biomass, and LAImax at Jokioinen (Fig. 3a). Compared with the Free-Air Carbon dioxide Enrichment (FACE) experiment data in the literature (Table S10), the simulated impacts of elevated $\mathrm{CO}_{2}$ on LAImax, ET, biomass and yield might be beyond the observation ranges of available FACE experiments for some models such as SI (Fig. 2). For each individual model, changes in grain yield were significantly and positively correlated with changes in above-ground biomass and LAImax, and changes in above-ground biomass were significantly and positively correlated with changes in LAImax (Tables S12-S19).

\subsection{Responses of crop growth and yield to temperature change}

Barley maturity date, and consequently growth duration, was sensitive to temperature change. For all the models, maturity date was delayed with a decreased temperature and advanced with an increased temperature, but to different extents (Fig. 4a, b). ET during the growing period generally increased with decreasing temperature and decreased with increasing temperature, again with the models showing differing sensitivities (Fig. 4e, f). There were also large uncertainties in the responses of LAImax, biomass, and grain yield to temperature change among models. Changes in LAImax (Fig. 4c, d), biomass (Fig. 4g, h), and grain yield (Fig. 4i, j) with temperature change among the eight models diverged largely in terms of magnitude or even sign, particularly at Lleida. Six of the eight models use a biomass-dependent 

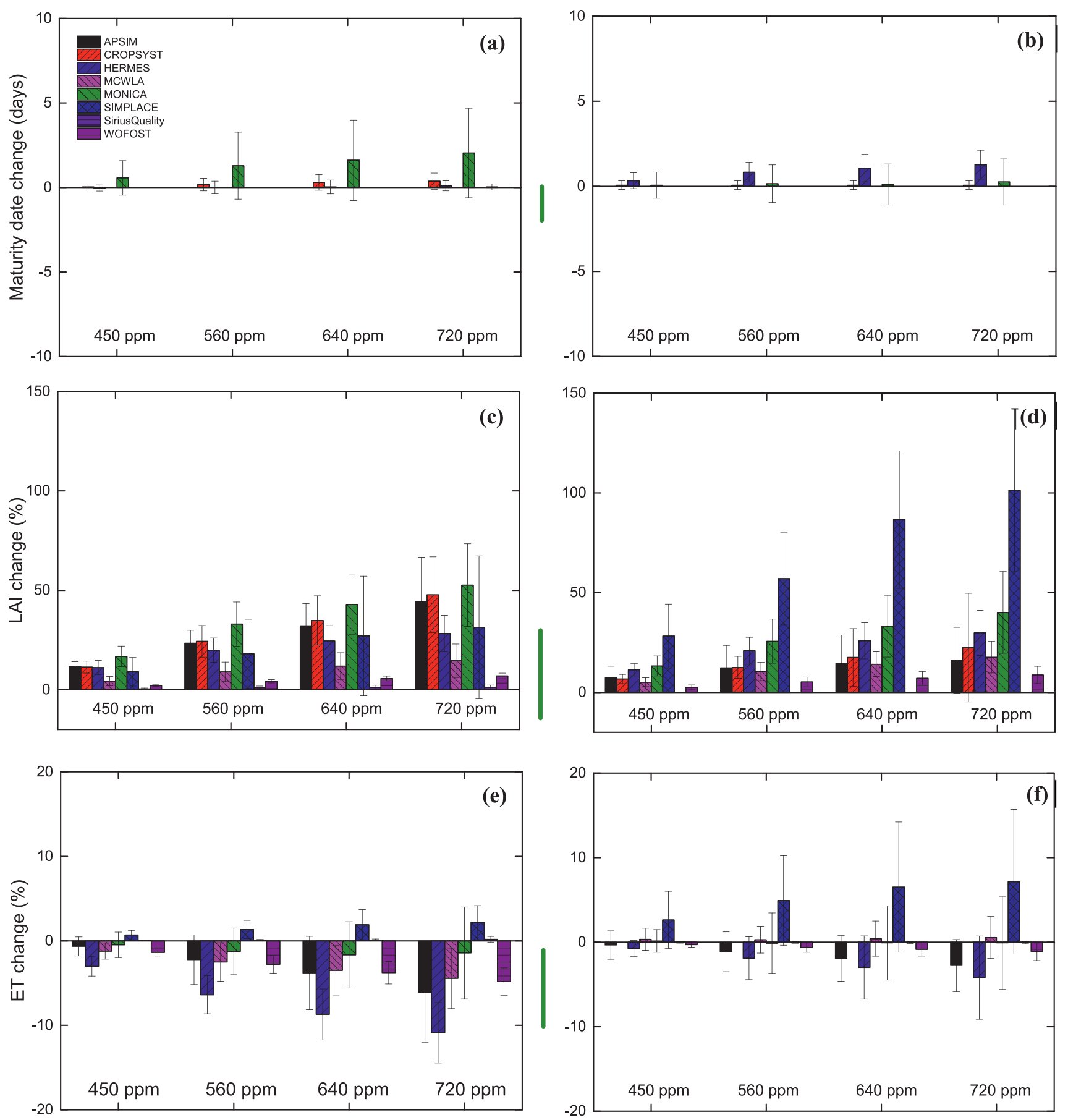

Fig. 2. Responses of the barley maturity date (a, b), LAI (c, d), ET (e, f), biomass ( $g, h$ ) and yield (i, j) to rising $\mathrm{CO}_{2}$ at Jokioinen, Finland (a, c, e, g, i) and Lleida, Spain (b, d, f, h, j) in the eight crop models. The ranges of elevated $\mathrm{CO}_{2}$ impacts at 500 to $600 \mathrm{ppm}$ based on the FACE experiments reported in literature (Table S2) are marked between the panels. The error bars represent the standard deviations of estimates based on the 30 years simulation results.

approach to model LAI. For these models, LAI dynamics and LAImax changed with crop above-ground biomass and, as a result, LAImax and grain yield decreased with increasing temperature and increased with decreasing temperature. In contrast, $M C$ and $S Q$ used a temperatureand water-driven approach to simulate LAI. For MC, LAImax increased slightly with increasing temperature at Jokioinen and more greatly at Lleida, resulting in the above-ground biomass and grain yield decreasing at Jokioinen and increasing at Lleida (Fig. 4). For SQ, LAImax decreased with increasing temperature at Jokioinen and increased slightly at Lleida, giving decreased above-ground biomass and grain yield at both sites (Fig. 4). MO and SI were most sensitive to temperature change at Jokioinen, and $C S, S I$, and $M C$ were most sensitive at
Lleida.

The standard deviation of the projected impacts of temperature change across the eight crop models showed that the models had the largest uncertainty in simulating temperature impacts on LAImax at both Lleida and Jokioinen, with the uncertainty increased substantially with temperature rising or falling (Fig. 3b). Compared with fieldwarming experiment data in the literature (Table S11), the simulated impacts of temperature increase on LAImax, biomass, and yield might be beyond the observation ranges of available field warming experiments for some models (Fig. 4). For each individual model, the responses of LAImax, biomass, and yield to temperature change were consistent at Jokioinen for most of the models (Fig. 4). Correlation 

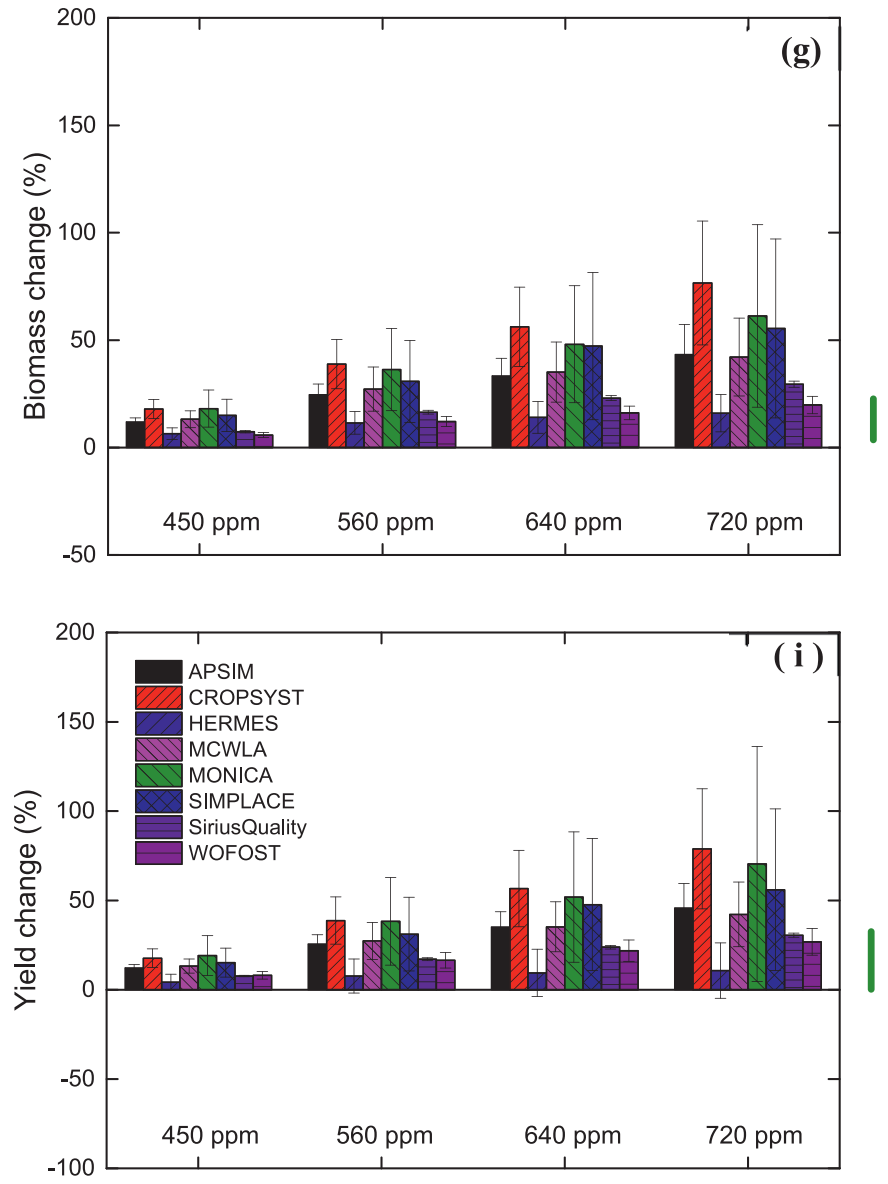

Fig. 2. (continued)
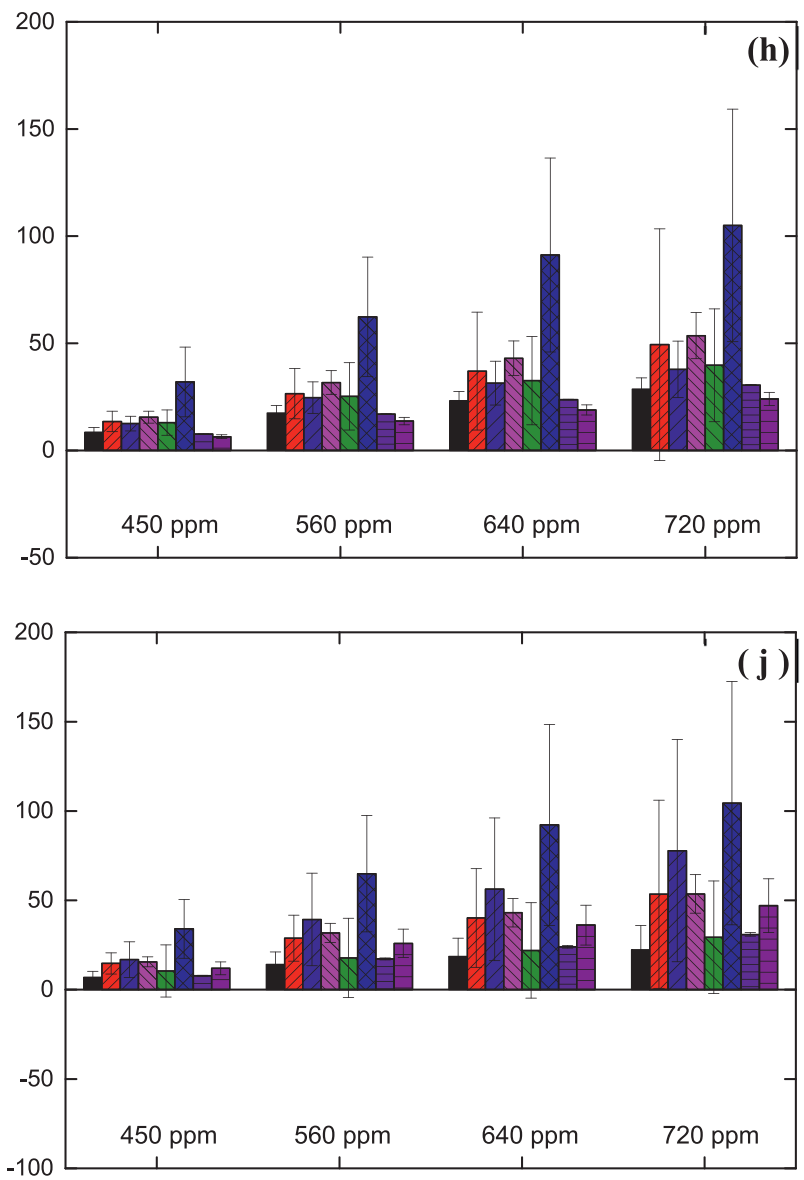

analyses showed that at Jokioinen for all the models grain yield responses to temperature change were significantly and positively correlated with changes in above-ground biomass, LAImax, maturity date, and ET. At Lleida, grain yield changes were significantly and positively correlated with changes in above-ground biomass for most of the models, in LAImax for AP, CS, MC, SI, and $S Q$, in maturity date for $S I$ and $S Q$, and in ET for AP, SI, $S Q$, and WO (Tables S12-S19).

\subsection{Responses of crop growth and yield to precipitation change}

At the both sites, barley maturity date was not sensitive to precipitation change except for $M O$ at Jokioinen (Fig. S2a, b). LAImax, ET, above-ground biomass, and grain yield decreased generally with decreasing precipitation and increased with increasing precipitation, however with different sensitivities among the eight models (Fig. S2). LAImax (Fig. S2c, d), ET (Fig. S2e, f), above-ground biomass (Fig. S2g, h), and grain yield (Fig. S2i, j) were not sensitive to precipitation change for SI, SQ and WO at Jokioinen, and for $A P, S I$, and SQ at Lleida. In contrast, they were sensitive for $M O$ and $C S$ at Jokioinen, and for $M O, C S$, and $M C$ at Lleida.

The standard deviation of the projected impacts of precipitation change across the eight crop models showed that crop models had the largest uncertainties in simulating impacts of precipitation change on yield, biomass, and LAImax at Jokioinen, with the uncertainty growing with decreasing or increasing precipitation (Fig. 3c). Nevertheless, the standard deviation was much less than that for the projected impacts of temperature increases. For each individual model, the responses of LAImax, ET, above-ground biomass, and grain yield to precipitation change were consistent. Correlation analyses showed that grain yield changes were significantly and positively correlated with changes in above-ground biomass, LAImax, and ET for the eight models, and in maturity date for $C S$ and $H E$ at Jokioinen. At Lleida, grain yield changes were significantly and positively correlated with changes in aboveground biomass and ET for the eight models, in LAImax for all the models except $A P$ and $W O$, and in maturity date for $C S$ and $H E$ (Tables S12-S19).

\subsection{Responses of crop growth and yield to solar radiation change}

Maturity date, and consequently growth duration, was not sensitive to solar radiation change for all the models except $M O$ and $S Q$ at Jokioinen (Fig. S3a, b). For most of the models, LAImax (Fig. S3c, d), ET (Fig. S3e, f), and above-ground biomass (Fig. S3g, h) decreased with decreasing solar radiation and increased with increasing solar radiation, although with quite different amplitudes among the models. In contrast, the reverse responses were found for LAImax and aboveground biomass for $C S$ and $M C$ at Jokioinen and for $M C$ at Lleida, mainly due to solar radiation-induced increases in ET (Fig. S3e, f) and subsequently drought stress on LAI development and photosynthesis rate, which mitigated the positive impact of solar radiation increase on photosynthesis rate. LAImax was most sensitive to solar radiation change for $S I$ at Lleida, but not sensitive for $S Q$ at Jokioinen and Lleida. Yield was directly correlated with solar radiation for $S I, S Q, A P, H E$, and $W O$ at Jokioinen and for $S I$ and $S Q$ at Lleida; however, the reverse responses were found for the other models (Fig. S3i, j). Biomass and yield were most sensitive to solar radiation change for $S I$ and $S Q$ at the both sites.

The standard deviation of the projected impacts of changes in solar radiation across the eight crop models showed that the models had the largest uncertainty in simulating impacts on yield, LAImax, and biomass at Lleida, with the uncertainty increasing as the solar radiation either decreased or increased (Fig. 3d). The standard deviation was 

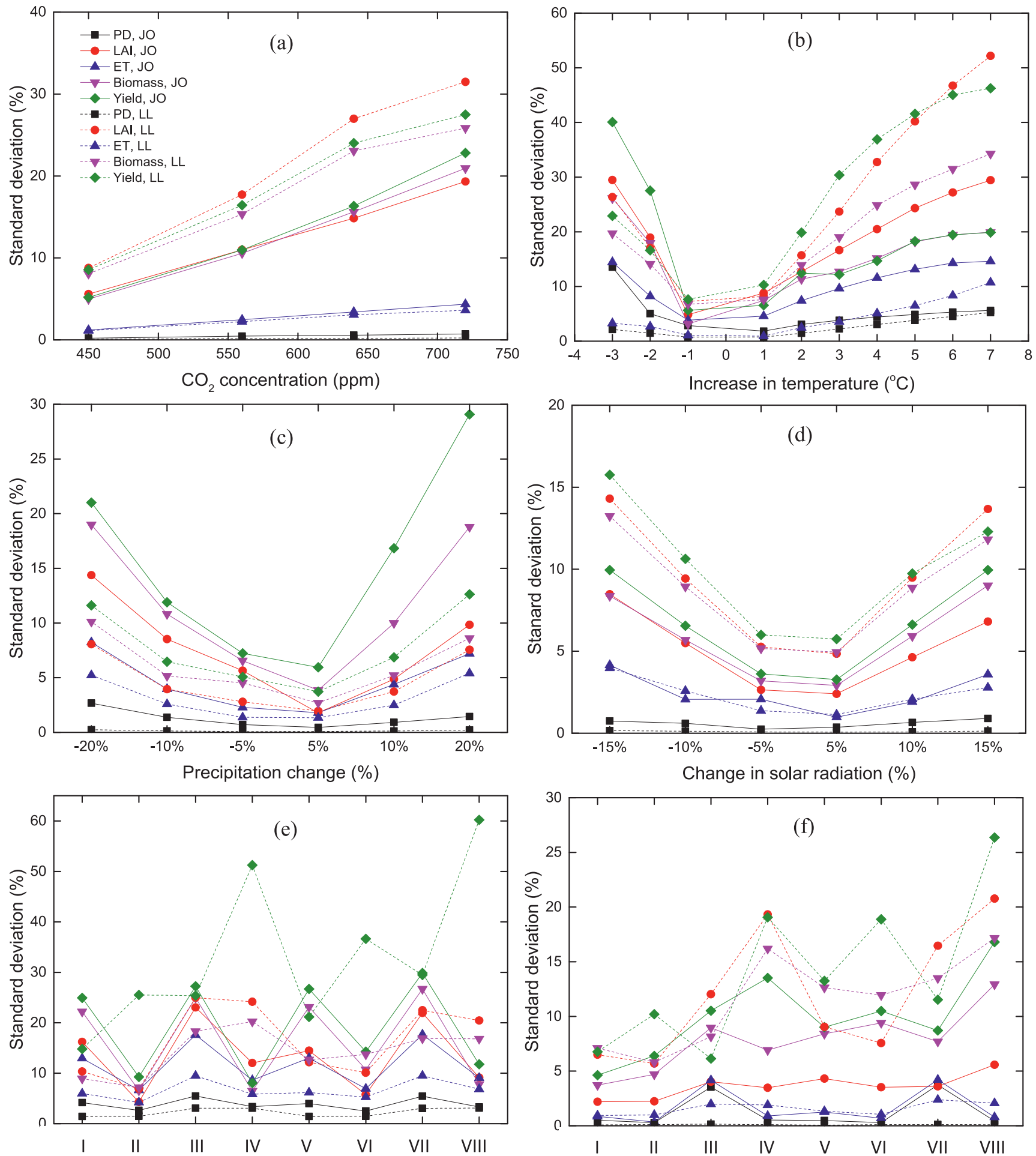

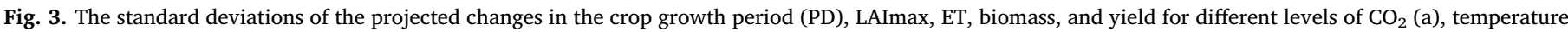

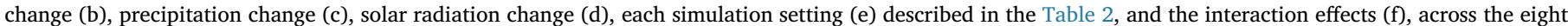
crop models at Jokioinen (JO) and Lleida (LL).

much less than that for the projected impacts of temperature or $\mathrm{CO}_{2}$ increases. For each individual model, correlation analyses showed that grain yield responses to solar radiation change were significantly and positively correlated with changes in above-ground biomass for all the models, in LAImax for most of the models, and in ET for all models except $M O$ and $C S$, and in maturity date for $C S, M O$, and $H E$ at Jokioinen. At Lleida, grain yield responses were significantly and positively correlated with changes in above-ground biomass for all models except $M O$ and $W O$, in LAImax for all models except $M O, H E$ and $W O$; in ET for all models except $M O$ and $W O$, and in maturity date for CS, MO, and HE (Tables S12-S19). 

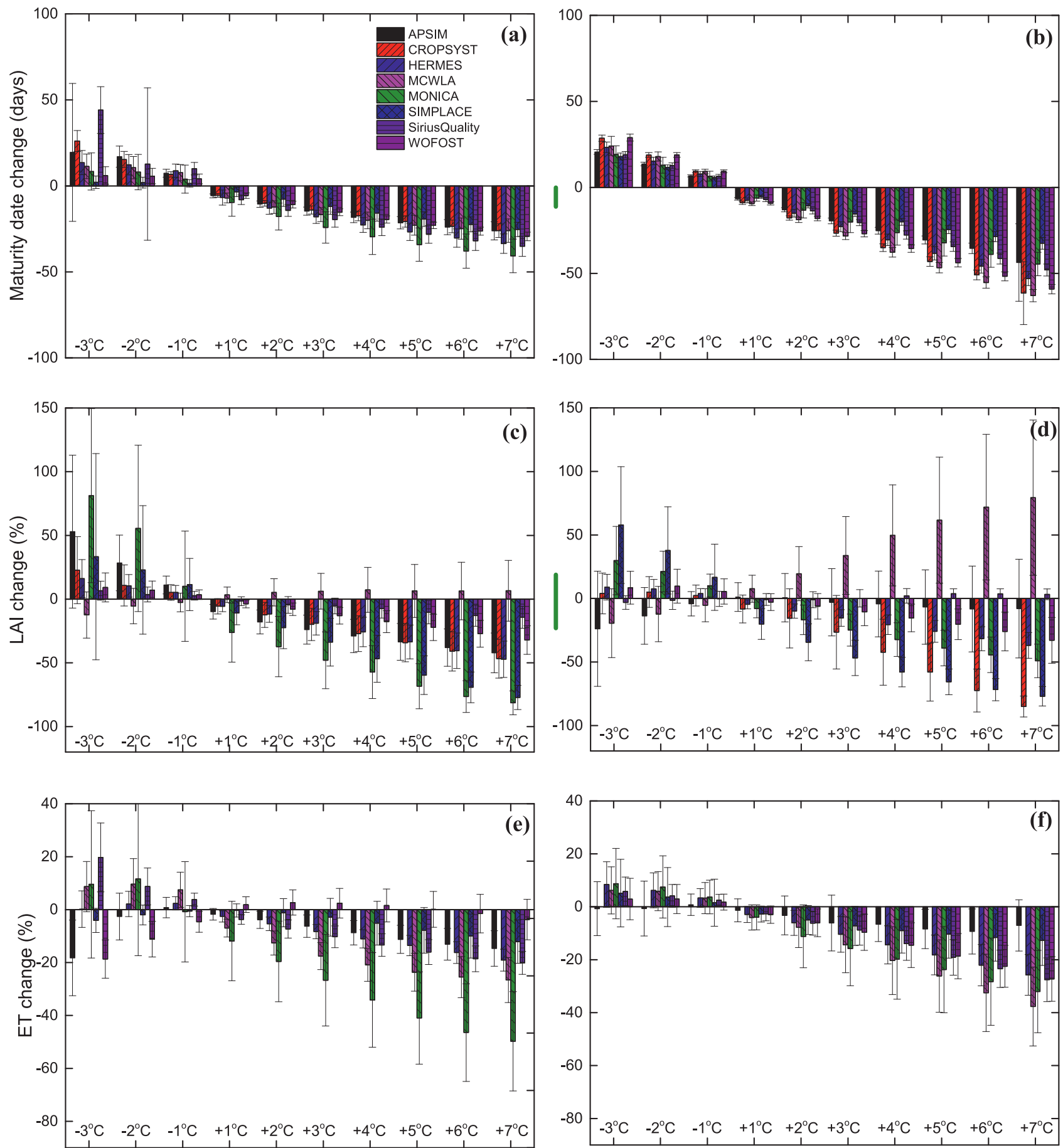

Fig. 4. Responses of the barley maturity date (a, b), LAI (c, d), ET (e, f), biomass (g, h) and yield (i, j) to change in temperature at Jokioinen, Finland (a, c, e, g, i) and Lleida, Spain (b, d, f, h, j) in the eight crop models. The ranges of impacts for 1.0 to $2.0{ }^{\circ} \mathrm{C}$ temperature increase based on the field warming experiments reported in literature (Table S3) are marked between the panels. The error bars represent the standard deviations of estimates based on the 30 years simulation results.

\subsection{Interactive impacts of temperature, precipitation, solar radiation, and $\mathrm{CO}_{2}$}

The responses of maturity date, LAImax, ET, above-ground biomass, and grain yield to the joint changes in temperature, precipitation, solar radiation, and $\mathrm{CO}_{2}$ greatly diverged among the eight models (Fig. 5). Under the joint impacts of temperature, precipitation, solar radiation, and $\mathrm{CO}_{2}$, barley maturity date was affected mainly by temperature change, and advanced more with climate warming, for all the models (Fig. 5a,b). In addition, maturity date was also affected by precipitation change for MO. In general, LAImax (Fig. 5c), above-ground biomass
(Fig. 5g), and yield (Fig. 5i) decreased more with increasing temperature and decreasing precipitation, which were alleviated by rising $\mathrm{CO}_{2}$, at Jokioinen. The models indicate that increasing precipitation and $\mathrm{CO}_{2}$ can compensate for the negative impacts of temperature increase for LAImax, above-ground biomass, and grain yield to some extent. At Lleida, LAImax (Fig. 5d), above-ground biomass (Fig. 5h), and grain yield (Fig. 5j) increased with increase in temperature, precipitation, and $\mathrm{CO}_{2}$ because milder winter can be beneficial for the winter barley cultivated there, although for $S I$ and $S Q$ they decreased with either decreasing precipitation or temperature increasing by $4{ }^{\circ} \mathrm{C}$. Changes in ET were dominated by temperature and precipitation changes, although 

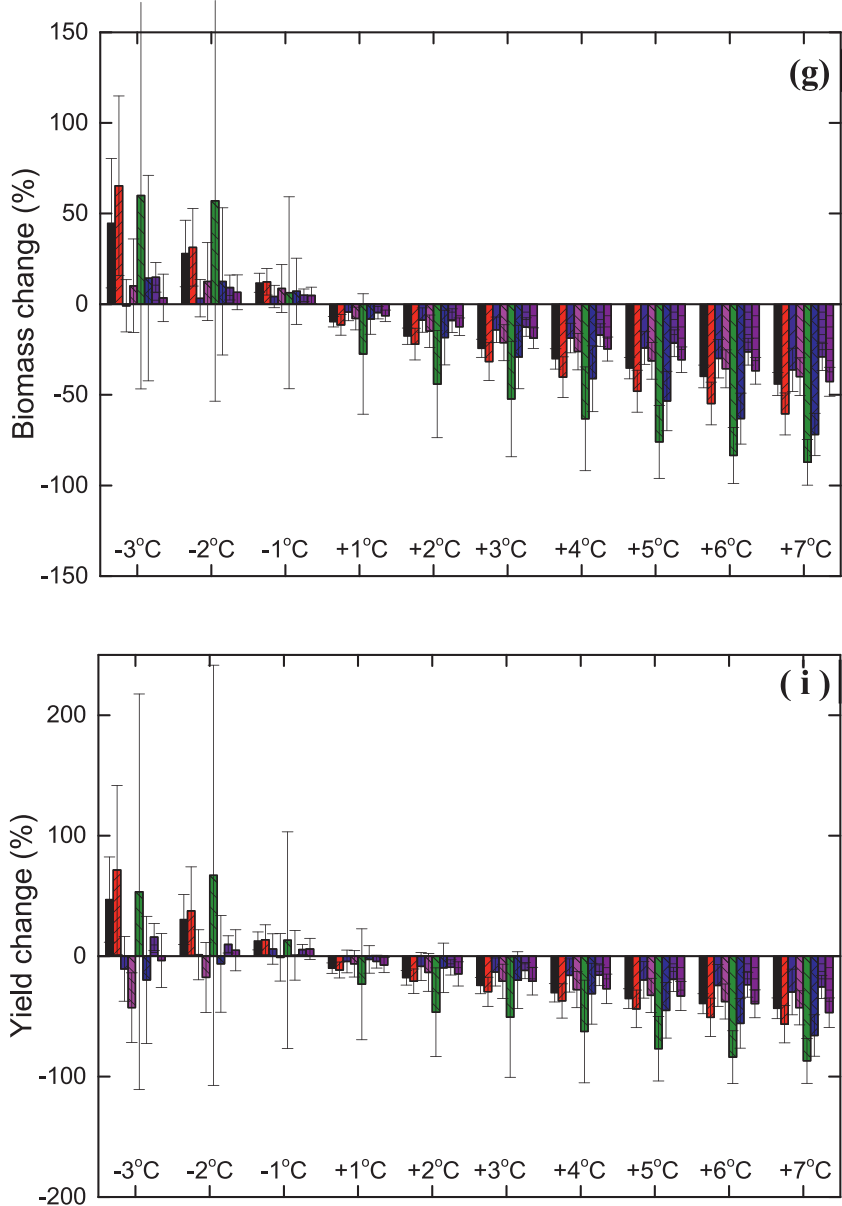

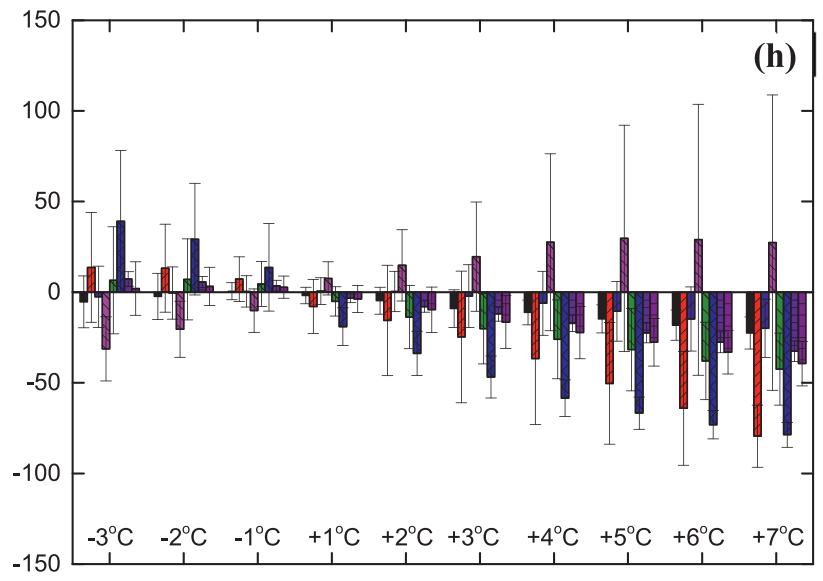

(h)

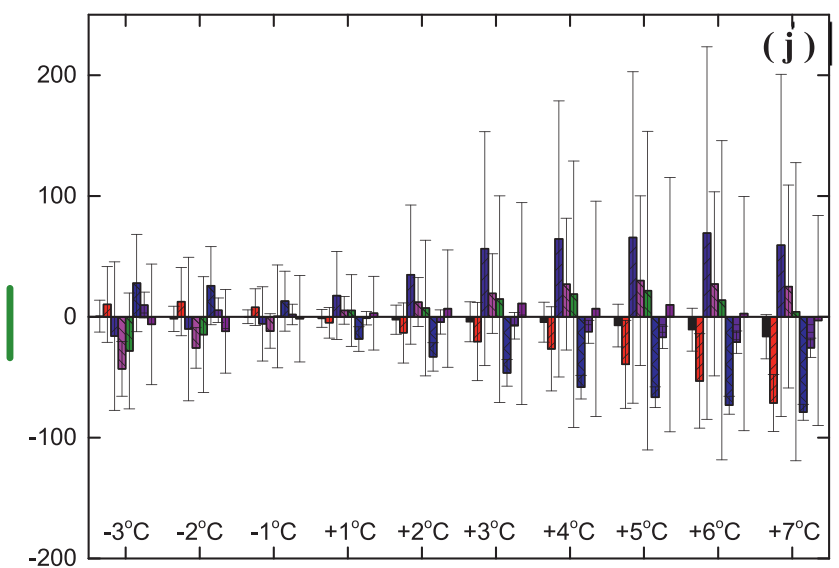

Fig. 4. (continued)

these changes were alleviated slightly by rising $\mathrm{CO}_{2}$, at both sites (Fig. 5e, f). During the growth period, ET was generally reduced in response to the joint changes in temperature, precipitation, solar radiation, and $\mathrm{CO}_{2}$ for all the models except $S I$ and $W O$ at Jokioinen and $S I$ at Lleida.

The standard deviation of the projected changes across the eight crop models showed that the crop models had the largest uncertainty in simulating the joint impacts on crop yield, LAImax, and biomass at Lleida (Fig. 3e). For each individual model, correlation analyses showed that grain yield changes were significantly and positively correlated with changes in above-ground biomass, ET, maturity date, and LAImax at Jokioinen. At Lleida, grain yield changes were significantly and positively correlated with changes in above-ground biomass for all the models except $A P$, in ET for all the models, in LAImax for all the models except $A P, H E, M O$, and $W O$, and in maturity date for $A P, S I$, and $S Q$ (Tables S12-S19).

The interaction effects of temperature, precipitation, solar radiation and $\mathrm{CO}_{2}$ on crop development, water use, growth, and yield greatly varied among the eight crop models in terms of magnitude and even change sign, and moreover were site, process, and model dependent (Fig. S4). Maturity date was much affected by high temperature and drought interactions for $M O$ at Jokioinen (Fig. S4a, b). LAImax was negatively affected by the interaction effects for most of the models at Jokioinen and for $H E, M C, M O$, and $S I$ at Lleida, but positively for $C S$ and $A P$ at Lleida (Fig. S4c, d). ET was strongly influenced by the interaction effects for $M O$ and $M C$ at Jokioinen, and for $M C, H E$, and $M O$ at Lleida (Fig. S4e, f). Above-ground biomass was greatly affected by interactions for $C S, M C$, and $M O$ at Jokioinen, and for $C S, M C$, SI, and $S Q$ at Lleida (Fig. S4g, h). Grain yield was affected by interactions for $C S, M C$, and $M O$ at Jokioinen, and for $H E, M C, S I$, and $S Q$ at Lleida (Fig.
S4i, j). For $H E$ and $W O$, biomass was not significantly affected by the interactions, but grain yield was. In general, the interaction effects were not significant for $A P$ and $W O$. The standard deviation of the projected changes across the eight crop models showed that crop models had the largest uncertainty in simulating the interaction effects on crop yield, LAImax, and biomass at Lleida (Fig. 3f).

\subsection{Summary of comparisons among key processes and among crop models}

Across the eight models and the settings in sensitivity analyses, the standard deviations of simulated changes in maturity date, LAImax, ET, aboveground biomass, and yield in response to changes in $\mathrm{CO}_{2}$, temperature, precipitation, solar radiation, all the climate factors and their interactions, were compared. The results showed that temperature and $\mathrm{CO}_{2}$ relationships in the models were the major sources of the large uncertainties in simulating climate change impacts, in particular for LAI development and biomass accumulation (Fig. 6).

Owing to the uncertainty in simulating the fundamental processes of crop growth and productivity, there were large uncertainties in simulating crop responses to changes in each climate variable and their interactions. We summarized and compared yield responses to changes in temperature $\left(+2{ }^{\circ} \mathrm{C}\right.$ at both Jokioinen and Lleida), precipitation (increasing by $10 \%$ at Jokioinen and reducing by $10 \%$ at Lleida), solar radiation (increasing by $10 \%$ at both Jokioinen and Lleida), and $\mathrm{CO}_{2}$ (increasing by $200 \mathrm{ppm}$ at both Jokioinen and Lleida), as well as their combinations, among the eight crop models (Fig. 7). The simulated yield responses to each climate variable, their combinations, and their interactions were quite different among the models in terms of magnitude and even change sign, which illustrated why crop models diverge substantially in climate impact projections. The uncertainties that 

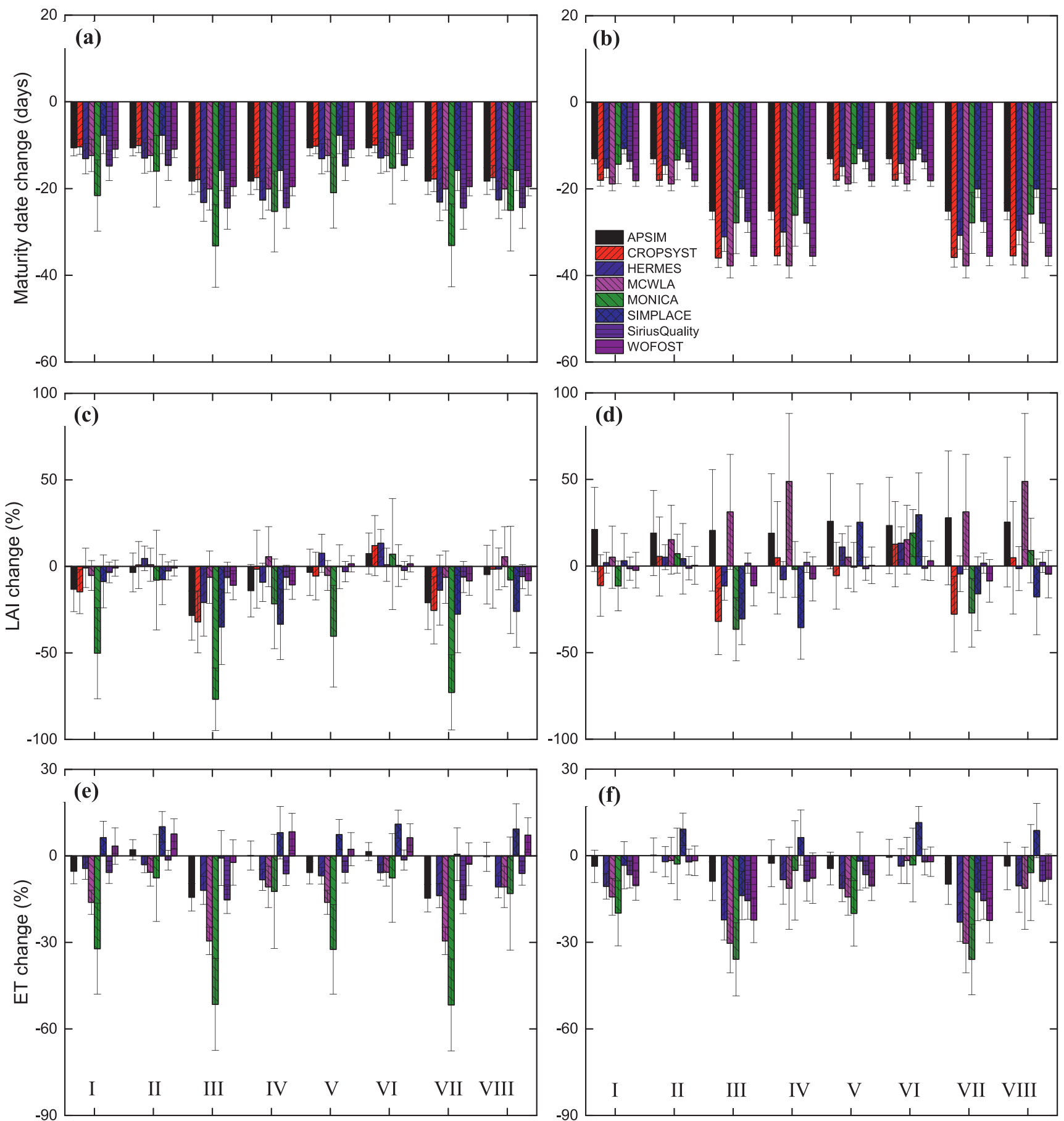

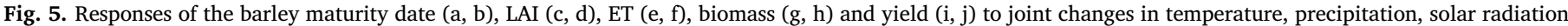

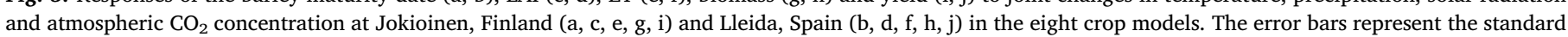
deviations of estimates based on the 30 years simulation results. The simulation settings are described in the Table 2 .

originated from the simulations of crop responses to temperature and $\mathrm{CO}_{2}$ fertilization effects were particularly large. The impacts of each climate variable on crop growth and productivity were offset or additive, resulting in large discrepancies in climate impact projections.

\section{Discussion}

4.1. Why do crop models diverge substantially in climate impact projections?

The present study provides insights into how crop models diverge in simulating the major processes of crop development, growth, water use, and yield formation in response to changes in temperature, precipitation, solar radiation, $\mathrm{CO}_{2}$, and their interactions. The divergences can be ascribed to the large differences in model structures among the eight examined crop models (Tables S2-S9). For example, although most of the models accounted for the impacts of temperature, photoperiod, and vernalization on crop development, they did this using different methods, with the result that the responses of crop maturity to temperature changes have different sensitivities among them. $M O$ also accounted for the impacts water and nitrogen stresses on crop phenological development with a stress factor (Table S6). As a consequence, 

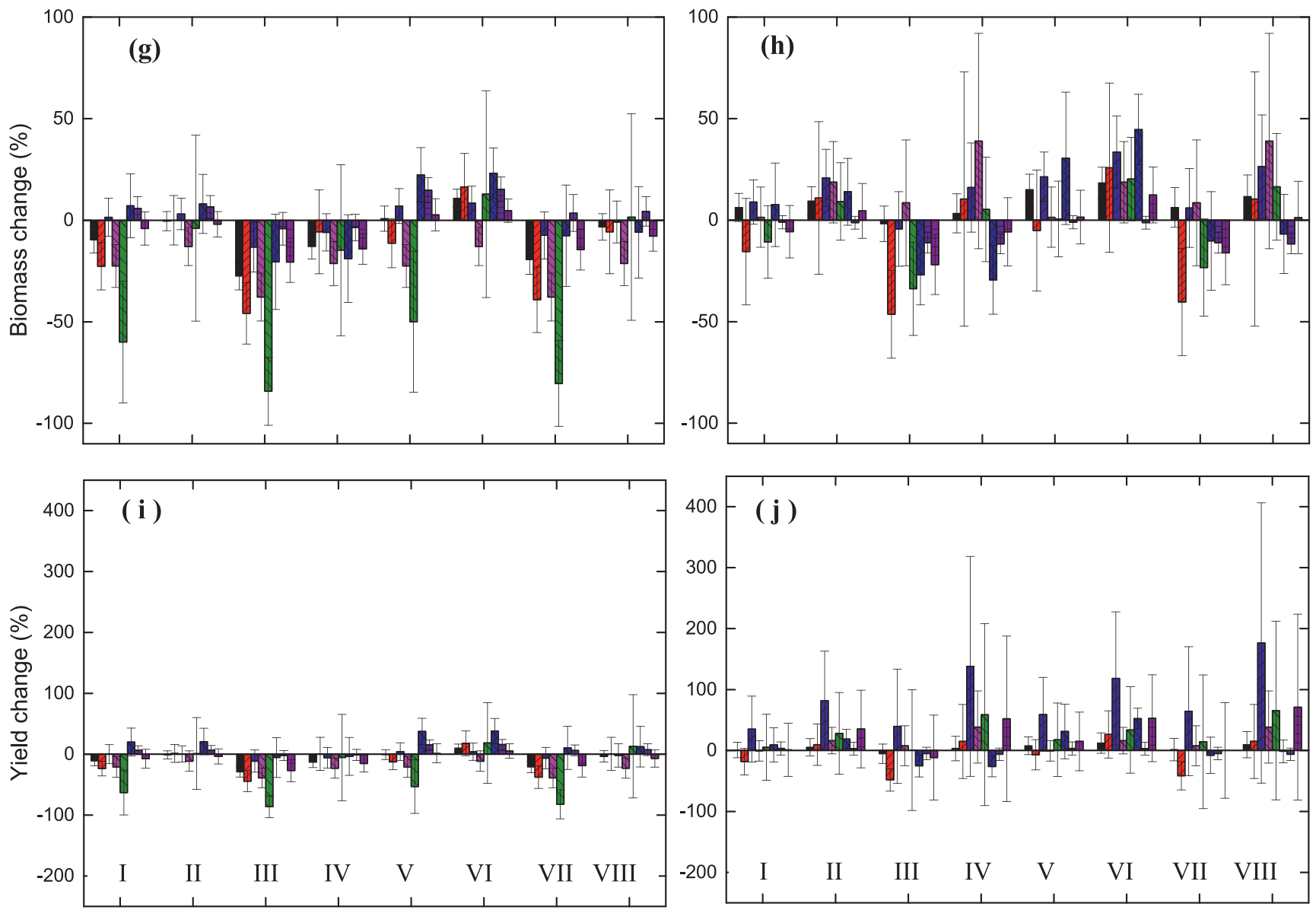

Fig. 5. (continued)

crop maturity was most sensitive to precipitation, solar radiation, $\mathrm{CO}_{2}$, and the interactions between climate variables for the model. Different from the other models, SI didn't account for the impacts of $\mathrm{CO}_{2}$ on evapotranspiration, as a consequence, the simulated evapotranspiration by the model increased with rising $\mathrm{CO}_{2}$ concentration.

The results showed that temperature and $\mathrm{CO}_{2}$ relationships in the models were the major sources of the large uncertainties in simulating climate change impacts, in particular for LAI development and biomass accumulation (Fig. 6). All the models except $M C$ and $S Q$ used various biomass-dependent approaches to model LAI. For most of these models, the impacts of temperature and $\mathrm{CO}_{2}$ on LAI development were simulated not directly, but indirectly through their influences on photosynthesis, respiration, or LUE, and consequently biomass accumulation. Therefore, the uncertainty in LAI simulations may be ascribed to the estimation of biomass, biomass partitioning to the leaves, or to both. The equations applied in these models to simulate the impacts of temperature and $\mathrm{CO}_{2}$ on photosynthesis, respiration, or LUE were quite diverse (Tables S2-S9), which resulted in the large divergences in the responses of biomass and LAI to changes in $\mathrm{CO}_{2}$ (Fig.2g,h,c,d) and temperature (Fig.4g,h,c,d). These models directly calculated the impact of $\mathrm{CO}_{2}$ on photosynthesis or LUE using a different $\mathrm{CO}_{2}$ impact function, except $H E, M C$, and $M O$ which used the Farquhar model (Tables S2-S9). These models calculated directly the impact of temperature on photosynthesis or LUE using a different temperature impact function, except $C S$ and SI, which accounted for it indirectly through temperature influence on crop water use efficiency $(C S)$ or on daily growth rate of LAI and senescence (SI) (Tables S2-S9).

It is these different modeling approaches and, $\mathrm{CO}_{2}$ and temperature relationships in the models that caused their substantial divergences in climate impact projections. For example, $\mathrm{CO}_{2}$ and temperature relationships in LAI development and photosynthesis in the $C S$ and $M C$ models were quite different (Tables S3, S5). In CS, LAI development was dependent on accumulated biomass, specific leaf area (SLA), and partition coefficient, while biomass was simulated using LUE or transpiration efficiency. The impacts of $\mathrm{CO}_{2}$ and temperature were indirectly modelled through ther influences on LUE and on transpiration efficiency (Tables S3). In MC, LAI development is driven by temperature and water. A process-based representation of the coupled $\mathrm{CO}_{2}$ and $\mathrm{H}_{2} \mathrm{O}$ exchanges, based on the Farquhar photosynthesis model, is applied to simulate photosynthesis, transpiration, and their $\mathrm{CO}_{2}$ and temperature relationships (Tables S5). As a result, LAI and biomass increased much more with rising $\mathrm{CO}_{2}$ for $C S$ than $M C$ at Jokioinen (Fig.2). At Lleida, LAI decreased with temperature increase because biomass decreased. maybe due to a shortening of crop growth duration for CS. By contrast, LAI and biomass increased with temperature increase for $M C$ because it stimulated LAI growth and photosynthesis rate (Fig.4). Also the interactive effects of temperature, precipitation, solar radiation, and $\mathrm{CO}_{2}$ concentration on LAI and biomass diverged substantially between the two models (Fig.S4).

Leaf area development is fundamental for crop photosynthesis, ET, biomass accumulation, and yield formation, directly affecting canopyintercepted radiation, photosynthesis rate, ET, and the relative share of evaporation and transpiration. For most of the models, yield was significantly correlated with above-ground biomass and LAImax, and above-ground biomass was significantly correlated with LAImax. Therefore, the impacts of temperature and $\mathrm{CO}_{2}$ on LAI development are expected to be the major causes for the large uncertainty in simulating above-ground biomass and grain yield. These findings are supported by several previous studies (Bannayan et al., 2005; Hasegawa et al., 2017).

It appears not to be practical at present to separate, across the multiple models analyzed here, the impacts of each single process, such as vernalization and water or nutrient stresses, because multiple 

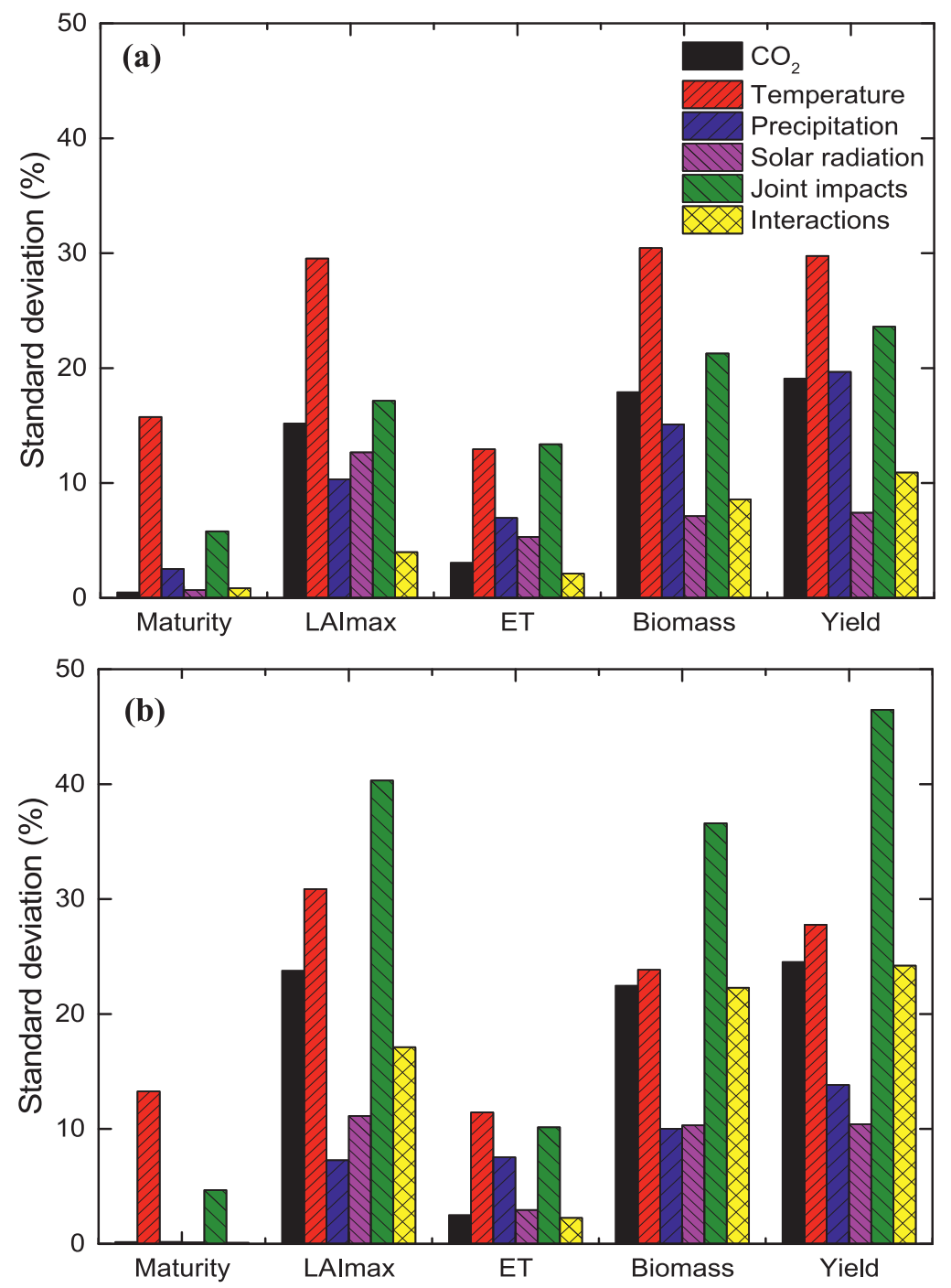

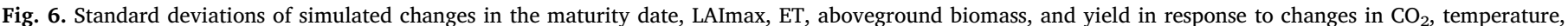
precipitation, solar radiation, all the climate factors and their interactions, by the eight crop models, at Jokioinen (a) and Lleida (b).

processes are closely interacting and interlinked. It may, however, be possible to investigate these details using a single model, using a set of same input data and parameters, focusing on a single process (e.g., crop phenology development) with a specific scheme of a modeling experiment (for example, comparing several alternative modeling approaches within a single model).

The sensitivity analyses in this study were used to dissect the reasons underlying the discrepancies in climate change impact projections by different crop models. The modeling settings for the sensitivity analyses were carefully designed to cover the projected climate change scenarios at the two sites in the 2050s and to address the key questions related to modeling of important crop growth and productivity processes. The results of the sensitivity analyses not only dissect the reasons underlying the discrepancies in climate change impact projections by different crop models, but also explain the projected climate change impacts on barley growth and yield in the 2050s. For examples, $H E$ projected a strong yield increase during the 2050s at Lleida (Fig. $1 \mathrm{j}$ ) because yield benefited greatly from temperature and $\mathrm{CO}_{2}$ increases, dropped moderately with a precipitation decrease, and suffered only slightly from a solar radiation increase, with little interaction between them in the model. By contrast, CS projected a severe yield decrease in the 2050s at Lleida (Fig. 1j) because yield benefited primarily from a $\mathrm{CO}_{2}$ increase, but dropped moderately with a temperature increase and precipitation decrease, with little impact from a solar radiation increase, and only small negative interactions between them in the model. Therefore, the large discrepancy in climate impact projections between the two models can be ascribed mainly to temperature and $\mathrm{CO}_{2}$ relationships (Figs. 2, 4, 7).

\subsection{Comparisons between controlled environment experimental data and model simulations}

Controlled environment experiments such as FACE (Ainsworth and Long, 2005; O'Leary et al., 2015; Kimball, 2016) or free-air temperature-increase experiments (Ottman et al., 2012; Cai et al., 2016; Chen et al., 2017; Fang et al., 2015) can provide information for benchmarking and improving models. Experiments on barley and wheat worldwide were collected from the literature (Tables S10 \& S11) and marked in Figs. 2 and 4. Barley and wheat are closely related and both $\mathrm{C} 3$ grasses, which have comparable responses to changes in $\mathrm{CO}_{2}$ concentration and temperature (Ainsworth and Long, 2005). The experiments were not conducted in the study sites and thus the comparisons are approximate, although meaningful to some extent. In this regard, the simulated $\mathrm{CO}_{2}$ effects on LAImax, ET, above-ground biomass and grain yield might be beyond the reasonable ranges for some models. Likewise, the simulations of impacts of temperature increase on LAImax, and consequently photosynthesis rate, biomass, and yield need to be further improved for some models. 


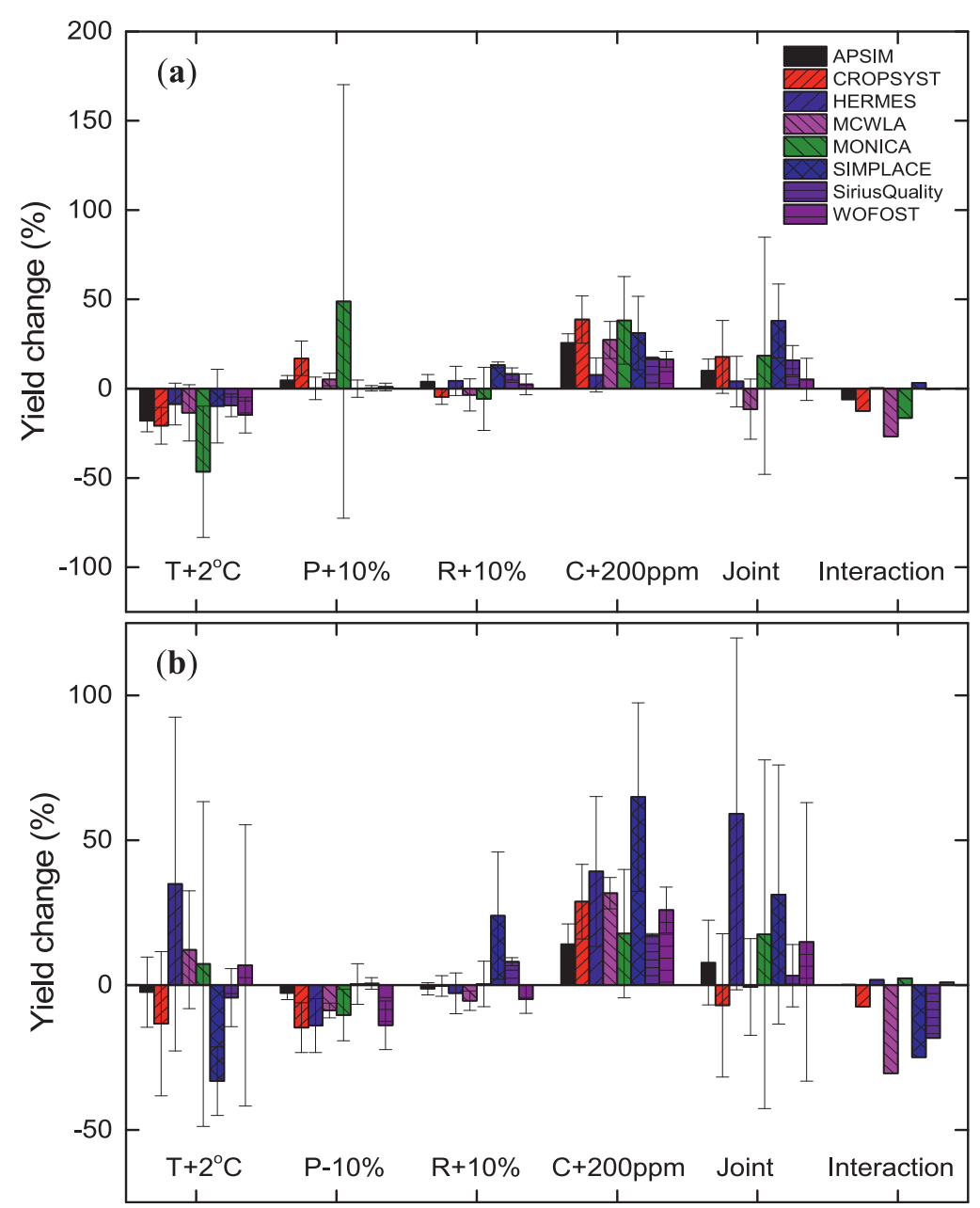

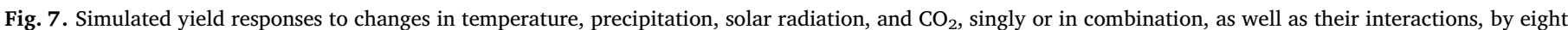
crop models at Jokioinen (a) and Lleida (b). The error bars represent the standard deviations of estimates based on the 30 years simulation results.

In addition, controlled-environment experiments can help to benchmark processes in models. For example, an experiment in Finland using controlled temperature and $\mathrm{CO}_{2}$ on a perennial reed canary grass showed that warming $\left(+3.5{ }^{\circ} \mathrm{C}\right.$ above outside ambient temperature) increased leaf growth, photosynthesis and above-ground biomass $(+30.3 \%$ for leaf and $+21.8 \%$ for stem) during early growth (Zhou et al., 2011). However, plant growth declined rapidly thereafter with a lower above-ground biomass $(-12.6 \%$ for leaf and $-9.1 \%$ for stem) at the end of growing season due to accelerated phenology regulation and consequent earlier growth senescence. Elevated $\mathrm{CO}_{2}$ (700 ppm) partially mitigated the adverse effects of high temperature and low soil moisture and, as a result, the combination of warming and elevated $\mathrm{CO}_{2}$ did not significantly increase above-ground biomass (Zhou et al., 2011). Compared with the experiment, it seems that most of these processes have been reasonably well incorporated in the eight crop models, except that warming increased leaf growth at early stages (Fig. 4c). This further confirmed that the response of LAI to temperature increase should be improved in these models.

The biophysical processes of crop development, water use, growth, and grain formation are finally subject to the interactions of multiple climate change factors, instead of a single factor. The interaction effects of multiple climate change factors could differ greatly from simple combinations of single-factor responses. The main effects of each individual factor could be depressed or amplified by the interactive effects of multiple factors (Luo et al., 2008). Two-way interactions of climate change factors on crop growth and yield, such as the interactive effects of temperature and $\mathrm{CO}_{2}$, water and $\mathrm{CO}_{2}$, and high temperature and drought have been studied in controlled environment field experiments (Kimball et al., 1995; Erbs et al., 2015; Cai et al., 2016; Wang et al., 2016). However, experiments on three-way or four-way interactions are scarce.

In general, the simulated crop responses to simultaneous changes in multiple climatic factors agree qualitatively with experimental evidence. Nevertheless, the eight crop models greatly diverged in their simulations of the interactions of temperature, precipitation, solar radiation, and $\mathrm{CO}_{2}$ on LAI development, biomass, and grain yield. The simulated interaction effects were also different at the two sites. Since the effects include two-way, three-way, and four-way interactions among temperature, precipitation, solar radiation, and $\mathrm{CO}_{2}$, they cannot easily be validated here. An improvement in simulating the main effects of each individual factor can reduce the uncertainty in simulating the interaction effects to some extent (Luo et al., 2008).

\subsection{Implications of this study for improvement of models and experimental design}

Although this study focused on barley models as an example, the results are widely applicable for other cereal crop models because they share the same modeling concepts and approaches (Palosuo et al., 2011; Rötter et al., 2012; Holzworth et al., 2014). Our results shed light on the reasons underlying the divergence among crop models in projecting climate change impacts, and provide suggestions for improving the models. For example, for the six crop models that use a biomass-dependent approach to simulate LAI development, their responses to 
climate change regarding biomass accumulation, biomass partitioning or both should be improved. Priority should be given to the impacts of temperature and $\mathrm{CO}_{2}$ increases on LAI development for each of the eight models. While this biomass-dependent approach has been shown to simulate leaf area development fairly well under a range of current environments (e.g., Gaydon et al., 2017), it however greatly overestimates leaf area development under elevated $\mathrm{CO}_{2}$ (Bannayan et al., 2005). The approach is strongly dependent on the simulated biomass, developmental stage- or thermal time-dependent leaf-stem partitioning, and SLA. Most importantly, it does not account for the uncoupling of leaf expansion and photosynthesis under water deficit (Muller et al., 2011) and elevated $\mathrm{CO}_{2}$ (Ainsworth and Long, 2005), and the very different temperature sensitivities of these two processes (Asseng et al., 2013, 2015; Wang et al., 2017). Furthermore, biomass is subject to complex interactions among nitrogen, $\mathrm{CO}_{2}$, temperature, and water feedbacks between photosynthetic rate and organ growth and size. Source-sink relationships may significantly modify photosynthesis rate, partitioning, and biomass accumulation over time under elevated $\mathrm{CO}_{2}$ (Boote and Loomis, 1991; Grace, 1997), and biomass partitioning to leaves can be reduced by elevated $\mathrm{CO}_{2}$ (Kim et al., 2003a, 2003b). Furthermore, developmental stages may not capture the allometric relationship between LAI and biomass (Ratjen et al., 2018). Leaf-stem partitioning and SLA are not independent due to the allometric relationship between LAI and biomass, and LAI may explain canopy SLA better than developmental traits (Ratjen et al., 2018). However, these mechanisms are rarely represented in current crop models. As a possible solution, the leaf-stem partitioning and SLA could be simulated based on LAI dynamics instead of developmental stage or thermal time (Ratjen et al., 2018). Alternatively, leaf area development could be simulated based on the availability of nitrogen rather than biomass (Jamieson and Semenov, 2000; Sinclair et al., 2003; Martre and Dambreville, 2018), which could improve the simulations of $\mathrm{CO}_{2}$ responses and capture their secondary processes (Vanuytrecht and Thorburn, 2017). Temperature impact functions and the cardinal temperatures in simulating crop phenological development, LAI development, photosynthesis rate, ET, and yield formation need to be further validated based on data from free-air temperature-increase experiments (Wang et al., 2017).

The results of this study also have important implications for the design of controlled-environment experiments in order to close the knowledge gaps, improve our understanding of the mechanisms of climate change impacts on crop development, growth, water use, and grain formation, and improve crop models. For example, the impacts of different levels of temperature and $\mathrm{CO}_{2}$ changes on many physiological and developmental phenomena need to be conducted in contrasting environments, such as Boreal vs. Mediterranean. The tradeoff between the effects of solar radiation increase on photosynthetic rate and drought stress need to be investigated further. Since for some models simulated yield changes were inconsistent with above-ground biomass changes, the impacts of extreme temperature, solar radiation, and precipitation on grain formation processes also deserve more studies. Finally, the three-way or four-way interactions of multiple climate change factors on crop development, growth, water use, and yield formation need to be investigated experimentally. Such knowledge and data are not available so far, but essential to improve the current crop models.

\section{Conclusions}

In this study, a new comprehensive analysis was conducted to look holistically at the reasons why crop models diverge substantially in climate impact projections and to investigate which biophysical processes and knowledge gaps are key factors affecting this uncertainty and should be given the highest priorities for improvement. Eight barley models and eight climate projections for the 2050s were applied to investigate the uncertainty from crop model structure in climate impact projections for barley growth and yield at two sites. Furthermore, sensitivity analyses were conducted on the responses of major crop processes to major climatic variables including temperature, precipitation, irradiation, and $\mathrm{CO}_{2}$, as well as their interactions, for each of the eight crop models. We showed that the temperature and $\mathrm{CO}_{2}$ relationships in the models were the major sources of the large discrepancies among the models in climate impact projections. In particular, the impacts of increases in temperature and $\mathrm{CO}_{2}$ on leaf area development were identified as the major causes for the large uncertainty in simulating changes in evapotranspiration, above-ground biomass, and grain yield. The findings shed light on the reasons underlying the divergence among crop models in projecting climate change impacts, and provide suggestions for model improvement and experimental design. The advancements in understanding the basic processes and thresholds by which climate warming and $\mathrm{CO}_{2}$ increases will affect leaf area development, crop evapotranspiration, photosynthesis, and grain formation in contrasting environments should be stressed for modeling their impacts.

\section{Declaration of Competing Interest}

None.

\section{Acknowledgements}

This study was carried out in the context of CropM within the FACCE-MACSUR knowledge hub (031A103B). FT and TP were supported by the Academy of Finland through projects AI-CropPro (decision no. 316172) and DivCSA (decision no. 316215) and Natural Resources Institute Finland through strategic projects ClimSmartAgri and Boost-IA. RPR was supported by the German Federal Ministry of Education and Research via the 'Limpopo Living Landscapes' project within the SPACES program (grant number 01LL1304A) and by the IMPAC^ 3 project funded by the German Federal Ministry of Education and Research (FKZ 031A351A). MIM, LR and MRR (CEIGRAM-UPM) were supported by MULCLIVAR CGL2012-38923-C02-02 from MINECO and by MACSUR01-UPM from INIA within FACCE-JPI. HH, TG and FE were financially supported by the German Federal Ministry of Food and Agriculture (BMEL) through the Federal Office for Agriculture and Food (BLE), (2851ERA01J), and thank Andreas Enders and Gunther Krauss (INRES, University of Bonn) for support. KCK and CN were supported by German Ministry of Education and Research (BMBF), 031B0039C. PM was supported by the European Union's Seventh Framework Programme (FP7/2007-2013; grant no. FP7-613556) and the FACCEMACSUR project (031A103B) through the metaprogramme on Adaptation of Agriculture and Forests to Climate Change (AAFCC) of the French National Institute for Agricultural Research (INRA). The work of AHS was carried out under the FACCE-JPI project ClimBar (Academy of Finland decision 284987). CD and RF were funded by JPI FACCE MACSUR2 through the Italian Ministry for Agricultural, Food, and Forestry Policies. Rothamsted Research receives grant-aided support from the Biotechnology and Biological Sciences Research Council (BBSRC) Designing Future Wheat project (BB/P016855/1). Financial support from these projects is gratefully acknowledged. The authors declare no conflict of interest.

\section{Supplementary materials}

Supplementary material associated with this article can be found, in the online version, at doi:10.1016/j.agrformet.2019.107851.

\section{References}

Ainsworth, E.A., Long, S.P., 2005. What have we learned from 15 years of free-air $\mathrm{CO}_{2}$ enrichment (FACE)? A meta-analytic review of the responses of photosynthesis, canopy properties and plant production to rising $\mathrm{CO}_{2}$. New Phytol. 165, 351-372. 
Angulo, C., Rötter, R., Lock, R., Enders, A., Fronzek, S., Ewert, F., 2013. Implication of crop model calibration strategies for assessing regional impacts of climate change in Europe. Agric. For. Meteorol. 170, 32-46.

Asseng, S., Ewert, F., Martre, P., Rötter, R.P., Lobell, D.B., Cammarano, D., 2015. Rising temperatures reduce global wheat production. Nat. Clim. Chang. 5, 143-147.

Asseng, S., Ewert, F., Rosenzweig, C., Jones, J.W., Hatfield, J.L., Ruane, A.C., et al., 2013. Uncertainty in simulating wheat yields under climate change. Nat. Clim. Chang. 3, 827-832.

Bannyayan, M., Kobayashi, K., Kim, H., Lieffering, M., Okada, M., Mirza, S., 2005. Modelling the interactive effects of atmospheric $\mathrm{CO}_{2}$ and $\mathrm{N}$ on rice growth and yield. Field Crops Res. 93, 237-251.

Bassu, S., Brisson, N., Durand, J.L., Boote, K., Lizaso, J., Jones, J.W., et al., 2014. How do various maize crop models vary in their responses to climate change factors? Glob. Chang. Biol. 20, 2301-2320.

Boogaard, H.L., van Diepen, C.A., Rötter, R.P., Cabrera, J.M., Van Laar, H.H., 1998. User's Guide for the WOFOST 7.1 Crop Growth Simulation Model and WOFOST Control Center 5.1, Techn. Doc. 52. Alterra, WUR, Wageningen, pp. 144.

Boote, K.J., Loomis, R.S., 1991. The prediction of canopy assimilation. In: Boote, K.J., Loomis, R.S. (Eds.), Modeling Crop Photosynthesis-From Biochemistry to Canopy. CSSA Special Publication 19, Madison, WI, pp. 109-137.

Cai, C., Yin, X., He, S., Jiang, W., Si, C., Struik, P.C., Luo, W., Li, G., Xie, Y., Xiong, Y., Pan, G., 2016. Reponses of wheat and rice to factorial combinations of ambient and elevated $\mathrm{CO}_{2}$ and temperature. Glob. Chang. Biol. 22, 856-874.

Cantero-Martinez, C., Angas, P., Lampurlanes, J., 2003. Growth, yield and water productivity of barley (Hordeum vulgare L.) affected by tillage and $\mathrm{N}$ fertilization in Mediterranean semiarid, rainfed conditions of Spain. Field Crops Res. 84, 341-357.

Castañeda-Vera, A., Leffelaar, P.A., Álvaro-Fuentes, J., Cantero-Martínez, C., Mínguez, M.I., 2015. Selecting crop models for decision making in wheat insurance. Eur. J. Agron. 68, 97-116.

Challinor, A.J., Müller, C., Asseng, S., Deva, C., Nicklin, K.J., Wallach, D., et al., 2018. Improving the use of crop models for risk assessment and climate change adaptation. Agric. Syst. 159, 296-306.

Chen, J., Chen, C., Tian, Y., Zhang, X., Dong, W., Zhang, B., et al., 2017. Differences in the impacts of nighttime warming on crop growth of rice-based cropping systems under field conditions. Eur. J. Agron. 82, 80-92.

Dufresne, J.-L., Foujols, M.-A., Denvil, S., Caubel, A., Marti, O., Aumont, O., et al., 2013. Climate change projections using the IPSL-CM5 earth system model: from CMIP3 to CMIP5. Clim. Dyn. 40 (9-10), 2123-2165.

Dunne, J.P., John, J.G., Shevliakova, E., Stouffer, R.J., Krasting, J.P., Malyshev, S.L., et al., 2013. GFDL's ESM2 global coupled climate-carbon earth system models. Part II: carbon system formulation and baseline simulation characteristics. J. Clim. 26, 2247-2267.

Durand, J.L., Delusca, K., Boote, K., Lizaso, J., Manderschei, R., Weigel, H.J., et al., 2018. How accurately do maize crop models simulate the interactions of atmospheric $\mathrm{CO}_{2}$ concentration levels with limited water supply on water use and yield? Eur. J. Agron. $100,67-75$.

Erbs, M., Manderscheid, R., Luig, A., Kage, H., Weigel, H.J., 2015. A field experiment to test interactive effects of elevated $\mathrm{CO}_{2}$ concentration (FACE) and elevated canopy temperature (FATE) on wheat. Procedia Environ. Sci. 29, 60-61.

Ewert, F., Rötter, R.P., Bindi, M., Webber, H., Trnka, M., Kersebaum, K.-C., et al., 2015. Crop modelling for integrated assessment of risk to food production from climate change. Environ. Modell. Softw. 72, 287-303.

Fang, S., Cammarano, D., Zhou, G., Tan, K., Ren, S., 2015. Effects of increased day and night temperature with supplemental infrared heating on winter wheat growth in North China. Eur. J. Agron. 64, 67-77.

Gaydon, D.S., Balwinder-Singh, Wang, E., Poulton, P.L., Ahmad, B., Ahmed, F., et al., 2017. . Evaluation of the APSIM model in cropping systems of Asia. Field Crops Res. 204, 52-75.

Grace, J., 1997. Towards models of resource allocation by plants. In: Bazzaz, F.A., Grace, J. (Eds.), Plant Resource Allocation. Academic Press, pp. 303.

Hasegawa, T., Li, T., Yin, X., Zhu, Y., Boote, K., Baker, J., et al., 2017. Causes of variation among rice models in yield response to $\mathrm{CO}_{2}$ examined with Free-Air $\mathrm{CO}_{2}$ Enrichment and growth chamber experiments. Sci. Rep. 7, 14858.

Hazeleger, W., Wang, X., Severijns, C., Stefanescu, S., Bintanja, R., Sterl, A., et al., 2012. EC-Earth V2.2: description and validation of a new seamless earth system prediction model. Clim. Dyn. 39, 2611-2629.

Holzworth, D.P., Huth, N.I., deVoil, P.G., Zurcher, E.J., Herrmann, N.I., et al., 2014. APSIM - evolution towards a new generation of agricultural systems simulation. Environ. Modell. Softw. 62, 327-350.

Jamieson, P.D., Semenov, M.A., 2000. Modelling nitrogen uptake and redistribution in wheat. Field Crops Res. 68, 21-29.

Jones, C.D., Hughes, J.K., Bellouin, N., Hardiman, S.C., Jones, G.S., Knight, J., et al., 2011. The HadGEM2-ES implementation of CMIP5 centennial simulations. Geosci. Model Dev. 4, 543-570.

Kersebaum, K., 2007. Modelling nitrogen dynamics in soil-crop systems with HERMES. Nutr. Cycling Agroecosyst. 77, 39-52.

Kimball, B.A., Pinter Jr., P.J., Garcia, R.L., UMorte, R.L., Wall, G.W., Hunsaker, D.J., 1995. Productivity and water use of wheat under free-air $\mathrm{CO}_{2}$ enrichment. Glob. Chang. Biol. 1, 429-442.

Kim, H.Y., Lieffering, M., Kobayashi, K., Okada, M., Mitchel, M.W., Gumpertz, M., 2003a. Effects of free air $\mathrm{CO}_{2}$ enrichment and nitrogen supply on the yield of temperate paddy rice crops. Field Crops Res. 82, 261-270.

Kim, H.Y., Lieffering, M., Kobayashi, K., Okada, M., Miura, S., 2003b. Seasonal changes in the effects of elevated $\mathrm{CO}_{2}$ on rice at three levels of nitrogen supply: a free air $\mathrm{CO}_{2}$ enrichment (FACE) experiment. Glob. Chang. Biol. 9, 826-837.

Kimball, B.A., 2016. Crop responses to elevated $\mathrm{CO}_{2}$ and interactions with $\mathrm{H}_{2} \mathrm{O}, \mathrm{N}$, and temperature. Curr. Opin. Plant Biol. 31, 36-43.

Li, T., Hasegawa, T., Yin, X., Zhu, Y., Boote, K., Adam, M., et al., 2015. Uncertainties in predicting rice yield by current crop models under a wide range of climatic conditions. Glob. Chang. Biol. 21, 1328-1341.

Lobell, D.B., Schlenker, W., Costa-Roberts, J., 2011. Climate trends and global crop production since 1980. Science 333, 616-620.

Luo, Y., Gerten, D., Le Maire, G., Parton, W.J., Wang, E., Zhou, Z., et al., 2008. Modeled interactive effects of precipitation, temperature, and $\left[\mathrm{CO}_{2}\right]$ on ecosystem carbon and water dynamics in different climatic zones. Glob. Chang. Biol. 14, 1986-1999.

Maiorano, A., Martre, P., Asseng, S., Ewert, F., Muller, C., Rötter, R.P., et al., 2017. Crop model improvement reduces the uncertainty of the response to temperature of multimodel ensembles. Field Crops Res. 202, 5-20.

Martre, P., Dambreville, A., 2018. A model of leaf coordination to scale-up leaf expansion from the organ to the canopy. Plant Physiol. 176, 704-716.

Martre, P., Jamieson, P., Semenov, M.A., Zyskowski, R.F., Porter, J.R., Triboi, E., 2006. Modelling protein content and composition in relation to crop nitrogen dynamics for wheat. Eur. J. Agron. 25, 138-154.

Martre, P., Wallach, D., Asseng, S., Ewert, F., Jones, J.W., Rötter, R.P., et al., 2015. Multimodel ensembles of wheat growth: many models are better than one. Glob. Chang. Biol. 21, 911-925.

Müller, C., Elliott, J., Chryssanthacopoulos, J., Arneth, A., Balkovic, J., Ciais, P., Deryng, D., Folberth, C., Glotter, M., Hoek, S., Iizumi, T., Izaurralde, R., Jones, C., Khabarov, N., Lawrence, P., Liu, W., Olin, S., Pugh, T., Ray, D., Reddy, A., Rosenzweig, C., Ruane, A., Sakurai, G., Schmid, E., Skalsky, R., Song, C., Wang, X., De Wit, A., Yang, H., 2017. Global gridded crop model evaluation: benchmarking, skills, deficiencies and implications. Geosci. Model Dev. 10, 1403-1422.

Muller, B., Pantin, F., Génard, M., Turc, O., Freixes, S., Piques, M., Gibon, Y., 2011. Water deficits uncouple growth from photosynthesis, increase C content, and modify the relationships between C and growth in sink organs. J. Exp. Bot. 62, 1715-1729.

Nazarenko, L., Schmidt, G.A., Miller, R.L., Tausnev, N., Kelley, M., Ruedy, R., et al., 2015. Future climate change under RCP emission scenarios with GISS Model E2. J. Adv. Model. Earth Syst. 7, 244-267.

Nendel, C., Berg, M., Kersebaum, K.C., Mirschel, W., Specka, X., Wegehenkel, M., et al., 2011. The MONICA model: testing predictability for crop growth, soil moisture and nitrogen dynamics. Ecol. Modell. 222, 1614-1625.

Olesen, J.E., Trnka, M., Kersebaum, K.C., Skjelvåg, A.O., Seguin, B., Peltonen-Sainio, P., Rossi, F., Kozyra, J., Micale, F., 2011. Impacts and adaptation of European crop production systems to climate change. Eur. J. Agron. 34, 96-112.

O’Leary, G.J., Christy, B., Nuttall, J., Huth, N., Stöckle, C., Basso, B., et al., 2015. Response of wheat growth, grain yield and water use to elevated $\mathrm{CO}_{2}$ under a Free Air $\mathrm{CO}_{2}$ Enrichment (FACE) experiment and modelling in a semi-arid environment. Glob. Chang. Biol. 21, 2670-2686.

Ottman, M.J., Kimball, B.A., White, J.W., Wall, G.W., 2012. Wheat growth response to increased temperature from varied planting dates and supplemental infrared heating. Agron. J. 104 (1), 7-16.

Palosuo, T., Kersebaum, K.C., Angulo, C., Hlavinka, P., Moriondo, M., Olesen, J.E., et al., 2011. Simulation of winter wheat yield and its variability in different climates of Europe: a comparison of eight crop growth models. Eur. J. Agron. 35, 103-114.

Pirttioja, N., Carter, T.R., Fronzek, S., Bindi, M., Hoffmann, H., Palosuo, T., et al., 2015. A crop model ensemble analysis of temperature and precipitation effects on wheat yield across a European transect using impact response surfaces. Clim. Res. 65, 87-105.

Porter, J.R., Gawith, M., 1999. Temperatures and the growth and development of wheat: a review. Eur. J. Agron. 10, 23-36.

Porter, J.R., Xie, L., Challinor, A., Cochrane, K., Howden, S.M., Iqbal, M.M., et al., 2014. Food security and food production systems. In: Field, C.B., Barros, V.R., Dokken, D.J., Mach, K.J., Mastrandrea, M.D., Bilir, T.E. (Eds.), Climate Change 2014: Impacts, Adaptation and vulnerability. Contribution of Working Group II to the Fifth Assessment Report of the Intergovernmental Panel On Climate Change. Cambridge University Press, Cambridge, UK, pp. 485-533.

Raddatz, T.J., Reick, C.H., Knorr, W., Kattge, J., Roeckner, E., Schnur, R., et al., 2007. Will the tropical land biosphere dominate the climate-carbon cycle feedback during the twenty-first century? Clim. Dyn. 29, 565-574.

Rashid, H., Hirst, A., Dix, M., 2013. Atmospheric circulation features in the ACCESS model simulations for CMIP5: historical simulation and future projections. Aust. Meteorol. Oceanogr. J. 63, 145-160.

Ratjen, A.M., Lemaire, G., Kage, H., Plénet, D., Justes, E., 2018. Key variables for simulating leaf area and N status: biomass based relations versus phenology driven approaches. Eur. J. Agron. 100, 110-117. https://doi.org/10.1016/j.eja.2018.04.008. In press.

Rosenzweig, C., Jones, J.W., Hatfield, J.L., Ruane, A.C., Boote, K.J., Thorburn, P., et al., 2013. The agricultural model intercomparison and improvement project (AgMIP). Agric. For. Meteorol. 170, 166-182.

Rötter, R.P., 2014. Robust uncertainty. Nat. Clim. Chang. 4, 251-252.

Rötter, R.P., Appiah, M., Fichtler, E., Kersebaum, K.C., Trnka, M., Hoffmann, M.P., 2018. Linking modelling and experimentation to better capture crop impacts of agroclimatic extremes - a review. Field Crops Res. 221, 142-156.

Rötter, R.P., Carter, T.R., Olesen, J.E., Porter, J.R., 2011. Crop-climate models need an overhaul. Nat. Clim. Chang. 1, 175-177.

Rötter, R.P., Hoffmann, M.P., Koch, M., Müller, C., 2018b. Progress in modelling agricultural impacts of and adaptations to climate change. Curr. Opin. Plant Biol. 45, 262-267. https://doi.org/10.1016/j.pbi.2018.05.009.

Rötter, R.P., Palosuo, T., Kersebaum, K.-C., Angulo, C., Bindi, M., Ewert, F., et al., 2012. Simulation of spring barley yield in different climatic zones of Northern and Central Europe: a comparison of nine crop growth models. Field Crops Res. 133, 23-36.

Ruane, A.C., Rosenzweig, C., Asseng, S., Boote, K.J., Elliott, J., Ewert, F., et al., 2017. An AgMIP framework for improved agricultural representation in integrated assessment 
models. Environ. Res. Lett. 12, 125003.

Salo, T., Palosuo, T., Kersebaum, K.C., Nendel, C., Angulo, C., Ewert, F., et al, 2016. Comparing the performance of 11 crop simulation models in predicting yield response to nitrogen fertilization. J. Agric. Sci. 154, 1218-1240.

Sinclair, T.R., Farias, J.R., Neumaier, N., Nepomuceno, A.L., 2003. Modeling nitrogen accumulation and use by soybean. Field Crops Res. 81, 149-158.

Smith, M.R., Myers, S.S., 2018. Impact of anthropogenic $\mathrm{CO}_{2}$ emissions on global human nutrition. Nat. Clim. Chang. 8, 834-839.

Stöckle, C.O., Kemanian, A.R., Nelson, R.L., Adam, J.C., Sommer, R., Carlson, B., 2014 Cropsyst model evolution: from field to regional to global scales and from research to decision support systems. Environ. Modell. Softw. 62, 361-369.

Swann, A.L., Hoffman, F.M., Koven, C.D., Randerson, J.T., 2016. Plant responses to increasing $\mathrm{CO}_{2}$ reduce estimates of climate impacts on drought severity. Proc. Natl. Acad. Sci. U.S.A. 113 (36), 10019-10024.

Tao, F., Yokozawa, M., Zhang, Z., 2009. Modeling the impacts of weather and climate variability on crop productivity over a large area: a new process-based model development, optimization, and uncertainties analysis. Agric. For. Meteorol. 149, $831-850$.

Tao, F., Feng, Z., Tang, H., Chen, Y., Kobayashi, K., 2017. Effects of climate change, $\mathrm{CO}_{2}$ and $\mathrm{O}_{3}$ on wheat productivity in Eastern China, singly and in combination. Atmos. Environ. 153, 182-193.

Tao, F., Rötter, R., Palosuo, T., Gregorio Hernández Díaz-Ambrona, C., Mínguez, M., Semenov, M., et al., 2018. Contribution of crop model structure, parameters and climate projections to uncertainty in climate change impact assessments. Glob. Chang. Biol. 24 (3), 1291-1307.

Vanuytrecht, E., Thorburn, P.J., 2017. Responses to atmospheric $\mathrm{CO}_{2}$ concentrations in crop simulation models: a review of current simple and semicomplex representations and options for model development. Glob. Chang. Biol. 23, 1806-1820.

Wallach, D., Nissanka, S.P., Karunaratne, A.S., Weerakoon, W.M.W., Thorburn, P.J.,
Boote, K.J., Jones, J.W., 2017. Accounting for both parameter and model structure uncertainty in crop model predictions of phenology: a case study on rice. Eur. J. Agron. 88, 53-62.

Wallach, D., Thorburn, P.J., 2017. Estimating uncertainty in crop model predictions: current situation and future prospects. Eur. J. Agron. 88, A1-A7.

Wang, E., Martre, P., Zhao, Z., Ewert, F., Maiorano, A., Rötter, R.P., et al., 2017. The uncertainty of crop yield projections is reduced by improved temperature response functions. Nat. Plants 3, 833 Article number: 17102.

Wang, J., Liu, X., Zhang, X., Smith, P., Li, L., Filley, T.R., Cheng, K., Shen, M., He, Y., Pan, G., 2016. Size and variability of crop productivity both impacted by $\mathrm{CO}_{2}$ enrichment and warming - a case study of 4 year field experiment in a Chinese paddy. Agric. Ecosyst. Environ. 221, 40-49.

Watanabe, S., Hajima, T., Sudo, K., Nagashima, T., Takemura, T., Okajima, H., et al., 2011. MIROC-ESM 2010: model description and basic results of CMIP5-20c3 m experiments. Geosci. Model Dev. 4, 845-872.

White, J.W., Hoogenboom, G., Kimball, B.A., Walla, G.W., 2011. Methodologies for simulating impacts of climate change on crop production. Field Crops Res. 124 357-368.

Zhang, S., Tao, F., 2013. Modeling the response of rice phenology to climate change and variability in different climatic zones: comparisons of five models. Eur. J. Agron. 4, 165-176.

Zhang, S., Tao, F., Zhang, Z., 2017. Uncertainty from model structure is larger than that from model parameters in simulating rice phenology in China. Eur. J. Agron. 87, 30-39.

Zhou, X., Ge, Z.M., Kellomäki, S., Wang, K.Y., Peltola, H., Martikainen, P., 2011. Effects of elevated $\mathrm{CO}_{2}$ and temperature on leaf characteristics, photosynthesis and carbon storage in aboveground biomass of a boreal bioenergy crop ( Phalaris arundinacea L.) under varying water regimes. Glob. Chang. Biol. 3, 223-234. 